\title{
Subduction earthquake sequences in a non-linear visco-elasto-plastic megathrust
}

\section{Journal Article}

Author(s):

Dal Zilio, Luca; Lapusta, Nadia; Avouac, Jean-Philippe; Gerya, Taras

Publication date:

2022-05-02

Permanent link:

https://doi.org/10.3929/ethz-b-000530485

Rights / license:

In Copyright - Non-Commercial Use Permitted

Originally published in:

Geophysical Journal International 229(2), https://doi.org/10.1093/gji/ggab521

Funding acknowledgement:

856559 - Fault Activation adn Earthquake Rupture (EC) 


\title{
Subduction earthquake sequences in a non-linear visco-elasto-plastic megathrust
}

\author{
Luca Dal Zilio ${ }^{\circledR},{ }^{1,2,3}$ Nadia Lapusta ${ }^{\oplus},{ }^{1,2}$ Jean-Philippe Avouac ${ }^{\oplus 1,2}$ and Taras Gerya ${ }^{\oplus 3}$ \\ ${ }^{1}$ Seismological Laboratory, California Institute of Technology (Caltech), Pasadena, CA 91125, United States. E-mail: luca.dalzilio@erdw.ethz.ch \\ ${ }^{2}$ Department of Mechanical and Civil Engineering, California Institute of Technology (Caltech), Pasadena, CA 91125, United States \\ ${ }^{3}$ Institute of Geophysics, Department of Geosciences, Swiss Federal Institute of Technology (ETH Zürich), CH-8093 Zürich, Switzerland
}

Accepted 2021 December 22. Received 2021 December 10; in original form 2021 August 22

\begin{abstract}
SUMMAR Y
We present a 2-D thermomechanical computational framework for simulating earthquake sequences in a non-linear visco-elasto-plastic compressible medium. The method is developed for a plane-strain problem and incorporates an invariant formulation of the classical rateand state-dependent friction law and an adaptive time-stepping, which allows the time step to vary by many orders of magnitude during a simulation. Long-term tectonic convergence is imposed by displacing a boundary at a constant rate, whereas temperature-dependent viscosity is solved using a rapidly converging Newton-Raphson scheme. The 2-D volume is discretized using finite differences on a fully staggered grid and marker-in-cell techniques. An adaptive free-surface approximation is used to modulate the air viscosity with the time step, which allows stresses to vanish on the free surface during the propagation of fast slipping events. We present a set of increasingly complex models in which we investigate how inertia, radiation damping, thermally activated non-linear rheology and off-megathrust splay-fault events affect sequences of seismic and aseismic slip on a simplified subduction megathrust. The new method provides a unique computational framework to analyse earthquake sequences and to connect forearc deformation with the dynamic properties of the megathrust, thus providing a physical link between observations spanning from slow interseismic strain accumulation to localized coseismic slip of individual earthquakes and post-seismic viscoelastic relaxation.
\end{abstract}

Key words: Earthquake dynamics; Numerical modelling; Seismicity and tectonics; Subduction zone processes; Rheology and friction of fault zones.

\section{INTRODUCTION}

Subduction interfaces - often called megathrusts - produce the largest earthquakes on Earth (e.g. Wang et al. 2012; Lay 2015). Despite decades of observational, laboratory and theoretical studies, the processes leading to large megathrust earthquakes are still a matter of debate (e.g. Kawamura et al. 2012; Kato \& Ben-Zion 2020). In particular, it remains unclear what controls earthquake complexity; persistent fault features, failure physics and dynamics of the failure process can all play a role (e.g. Ye et al. 2018). Continuous geophysical monitoring has shown that large megathrust earthquakes occur in the context of irregular interseismic strain accumulation, with static and dynamic stress changes causing multiple effects on the fault zone, such as post-seismic slip (often called afterslip), viscoelastic relaxation and eventually relocking of the fault (Wang et al. 2012; Bilek \& Lay 2018). Furthermore, decades of geophysical observations have demonstrated that subduction megathrusts are the locus of a wide spectrum of slip modes, ranging from the dynamic propagation of seismic rupture to slow-slip events of various durations and sizes, and to stable (aseismic) slip (e.g. Bürgmann 2018; Jolivet \& Frank 2020).

Seismological and geodetic data from different subduction zones, including rupture velocity, radiated energy, and the distribution of seismic and aseismic slip (Lay et al. 2012; Bilek \& Lay 2018), provides clear evidence of depth-dependent behaviour of subduction megathrusts (e.g. Lay et al. 2012; Ye et al. 2018). This depth dependence has been attributed to changes in fault properties (Huang et al. 2012; Noda \& Lapusta 2013), fluid pressure (Tobin \& Saffer 2009), the presence of weak sediments (Heuret et al. 2012), fault roughness and geometry (Wang \& Bilek 2011) and rigidity of the upper plate (Sallarès \& Ranero 2019). In particular, temperature is thought to constrain the downdip extent of the seismogenic zone. The latter is particularly important when the $\sim 350{ }^{\circ} \mathrm{C}$ isotherm is reached before the intersection of the megathrust with the forearc Moho (Oleskevich et al. 1999), consistent with the common view that temperature is the dominant factor controlling friction and viscoelastic behaviour of subduction megathrusts (e.g. Sibson 1982; Blanpied et al. 1991; Hyndman \& Wang 1993; Avouac 2015). Furthermore, the transition zone from seismogenic to aseismic deformation often involves a mix of episodic slow-slip events, 
low frequency earthquakes and seismic tremors (e.g. Peng \& Gomberg 2010; Beroza \& Ide 2011; Houston et al. 2011; Avouac 2015; Obara \& Kato 2016; Bürgmann 2018; Jolivet \& Frank 2020).

Both geodetic and seismological observations have increased dramatically over the past two decades, yet their short instrumental record makes it difficult to understand the maximum expected earthquake magnitude (McCaffrey 2008). Records of the relative sea level change extracted from corals may help to constrain the sequence of large events in the last centuries (e.g. Sieh et al. 2008; Philibosian et al. 2017), but defining the recurrence intervals and the long-term seismic pattern for a megathrust fault have proven to be problematic. In the meantime, progress in computing technology has led to the development of numerical models of sequences of seismic and aseismic slip that incorporate the physics governing earthquakes and slow-slip events (e.g. Tse \& Rice 1986; Ben-Zion \& Rice 1995; Lapusta et al. 2000; Lapusta \& Liu 2009). Further advance of this class of models have incorporated variable material properties (Kaneko et al. 2011; Erickson \& Dunham 2014), poroelastic effects (Heimisson et al. 2019), pore pressure evolution (Zhu et al. 2020), off-fault plasticity (Erickson et al. 2017; Thomas \& Bhat 2018), dilatant strengthening (Segall et al. 2010), semi-brittle rheologies (Goswami \& Barbot 2018; Lavier et al. 2021) and viscoelasticity (Lambert \& Barbot 2016; Barbot 2018; Allison \& Dunham 2018; Viesca \& Dublanchet 2018; Miyake \& Noda 2019). The increasing complexity in resolving multiscale earthquake source processes has also called for extensive efforts to verify codes and their reproducibility (Erickson et al. 2020; Jiang et al. 2021).

More recently, a new class of models has been developed to combine long-term geodynamic processes and short-term earthquake cycles (van Dinther et al. 2013b, a; Sobolev \& Muldashev 2017). In particular, this approach allows for simulating seismic behaviour in relation to the evolving tectonic forces, including elastic bending of the lithosphere (van Dinther et al. 2014), slab retreat and buoyancy forces (D'Acquisto et al. 2020; Dal Zilio et al. 2020a) in realistic subduction settings. However, due to simplifying assumptions, these simulations yield slip transients that are many orders of magnitude slower than earthquakes in nature. In a recent study, Herrendörfer et al. (2018) significantly improved this modelling approach by incorporating (i) an invariant formulation of the classical rate- and state-dependent friction equations and (ii) an adaptive time-stepping (Lapusta et al. 2000) to capture the evolution of dynamic ruptures. However, some other simplifications adopted in these simulations, for example linear rheology and the absence of temperature and gravity, have limited the possibility of comparing the model predictions with observations of the earthquake sequences in nature.

In this study, we present VELO2CYCLEs (Visco-ELastO 2-D Cycles of Earthquakes), a continuum mechanics modelling approach to simulate sequences of earthquakes and aseismic slip (SEAS) in a visco-elasto-plastic medium. The computational method is developed for a plane-strain problem of a thrust fault governed by rate-and-state friction. The fault and bulk rheology is controlled by temperature-dependent viscosity, which is given by a combination of diffusion and dislocation creep. Within the context of a time-stepping method, we solve the Navier-Stokes equations by incorporating inertia effects. We propose a finite difference method, as it is easy to program, efficient, and supports the marker-in-cell technique that can be applied to simulate large strains, as required to model long-term tectonic deformation (Gerya \& Yuen 2007; Gerya 2019).

Here, we present our newly developed methodology and demonstrate its versatility to tackle a broad range of challenging problems in computational earthquake physics. To test and illustrate the novel capabilities of this method, herein we present a set of increasingly complex models in which we investigate how inertia, radiation damping, thermally activated non-linear rheology and off-megathrust splay-fault events affect sequences of seismic and aseismic slip on a simplified subduction megathrust. In particular, the relatively simple model setup allows us to compare the modelling results against other computational methods in the literature and simple analytical solutions. In Section 2, we present the conceptual and mathematical model and state the continuum problem solved in this work. In Section 3, we present results and compare solutions for quasi-dynamic (QD) and fully dynamic (FD) simulations (Section 3.1), non-linear rheology (Section 3.2) and off-megathrust splay-fault events (Section 3.3). Finally, Section 4 analyses and interprets the results in the context of observations of large megathrust earthquakes and discusses future avenues for research through the use of this methodology.

\section{METHODOLOGY}

\subsection{Visco-elasto-plastic rheology and governing equations}

We assume a continuum, isotropic, Maxwell-type model. The mathematical description of a deforming continuum in a stationary gravity field is given by the following set of conservation equations for mass - eq. (A1), linear and angular momentum-eq. (A4), and energy-eq. (A5) under the plane-strain assumption:

$$
\begin{aligned}
& \frac{\mathrm{D} \rho}{\mathrm{D} t}+\rho \nabla \cdot \boldsymbol{v}=0, \\
& \rho \frac{\mathrm{D} \boldsymbol{v}}{\mathrm{D} t}-\nabla \cdot \underline{\underline{\sigma}}-\rho \boldsymbol{g}=0, \\
& \rho C_{p} \frac{\mathrm{D} T}{\mathrm{D} t}-\nabla \cdot(k \nabla T)=0,
\end{aligned}
$$

where $\rho$ is density, $\boldsymbol{v}$ the velocity vector, $\underline{\underline{\sigma}}$ is the Cauchy stress tensor, $\boldsymbol{g}$ is the gravity vector, $C_{p}$ the isobaric heat capacity, $T$ is the temperature and $k$ is the thermal conductivity. 
The stress is decomposed into a deviatoric and volumetric component:

$\underline{\underline{\sigma}}=\underline{\underline{\tau}}-p \underline{\underline{I}}$

where $\underline{\underline{\boldsymbol{\tau}}}$ is the deviatoric stress tensor, $p=-\frac{1}{3} \operatorname{Tr} \underline{\underline{\sigma}}$ is the pressure or the mean compressive stress, and $\underline{\underline{\boldsymbol{I}}}$ is the identity tensor.

The volumetric deformation is assumed to be purely elastic, with the bulk modulus $K$ defined as

$\frac{1}{K}=\frac{1}{\rho} \frac{\mathrm{D} \rho}{\mathrm{D} p}$

such that the time derivative of density in eq. (A1) satisfies the following:

$\frac{\mathrm{D} \rho}{\mathrm{D} t}=\frac{\rho}{K} \frac{\mathrm{D} p}{\mathrm{D} t}$.

The deviatoric deformation occurs as a combination of elastic, viscous, and plastic deformation. Components of the deviatoric strain-rate tensor are defined via spatial gradients of the velocity under the assumption of infinitesimal strain as follows:

$\dot{\varepsilon}_{i j}^{\prime}=\frac{1}{2}\left(\frac{\partial v_{i}}{\partial x_{j}}+\frac{\partial v_{j}}{\partial x_{i}}\right)-\frac{1}{3} \operatorname{Tr} \dot{\varepsilon}_{i j}$,

where $i$ and $j$ are coordinate indexes and $x_{i}$ and $x_{j}$ are spatial coordinates such that in 2-D we can define four tensor components. We assume that strain rate can be additively decomposed into its elastic, viscous and plastic components as

$\dot{\varepsilon}_{i j}^{\prime}=\left[\dot{\varepsilon}_{i j}^{\prime}\right]_{\text {viscous }}+\left[\dot{\varepsilon}_{i j}^{\prime}\right]_{\text {elastic }}+\left[\dot{\varepsilon}_{i j}^{\prime}\right]_{\text {plastic }}$.

The elastic part is defined as

$\left[\dot{\varepsilon}_{i j}^{\prime}\right]_{\text {elastic }}=\frac{1}{2 \mu} \frac{\tilde{\mathrm{D}}}{\tilde{\mathrm{D}} t}\left(\tau_{i j}\right)$

where $\mu$ is the shear modulus, while the differential operator $\tilde{\mathrm{D}} / \tilde{\mathrm{D}} t$ denotes the corotational time derivative- - that is, the local rates of change in the deviatoric stress with respect to translations, rotations, and/or deformation.

Viscous creep obeys either Newton's law of viscous friction or is computed in terms of deformation invariants and depends on strain rate, temperature and pressure (Ranalli 1995). The viscous behaviour of a rock is defined here via a single effective viscosity according to

$\eta_{\mathrm{eff}}=\frac{\tau_{\mathrm{II}}^{\prime}}{2 \dot{\varepsilon}_{\mathrm{II}(\mathrm{v})}^{\prime}}$,

where the $\tau_{\mathrm{II}}^{\prime}$ and $\dot{\varepsilon}_{\mathrm{II}(\mathrm{v})}^{\prime}$ denote the square root of the second invariant of the deviatoric stress and the viscous strain-rate tensors, respectively. The unified effective viscosity $\left(\eta_{\text {eff }}\right)$ is calculated as a combination of diffusion $\left(\eta_{\text {diff }}\right)$ and dislocation creep $\left(\eta_{\text {disl }}\right)$ :

$\eta_{\text {diff }}=\frac{1}{2} A_{d} \tau_{t r}^{1-n} \exp \left(\frac{E+p V}{R T}\right)$

$\eta_{\text {disl }}=A_{d} \tau_{\mathrm{II}}^{n-1} \exp \left(-\frac{E+p V}{R T}\right)$.

where $A_{d}$ is the pre-exponential factor, $n$ is the stress exponent, $E$ is the activation energy, $V$ is the activation volume, $R$ is the gas constant and $\tau_{t r}$ defines the stress transition between diffusion creep and dislocation creep, which is assumed to occur at $30 \mathrm{kPa}$ (Turcotte \& Schubert 2002 ). Dislocation creep is dominant for high-stress levels, while diffusion creep - a thermally activated mechanism-is dominant at low-stress conditions. When both diffusion and dislocation creep mechanisms are simultaneously active, the two viscous mechanisms are combined (Appendix A) while a Newton-Raphson scheme with quadratic convergence is used to obtain an effective viscosity ( $\left.\eta_{\text {eff }}\right)$ (Appendix B). The effective viscosity is then used to define the viscous contribution to the strain-rate tensor:

$\left[\dot{\varepsilon}_{i j}^{\prime}\right]_{\text {viscous }}=\frac{\tau_{i j}}{2 \eta_{\mathrm{eff}}}$.

Plastic (irreversible) deformation and frictional sliding is governed by rate- and state-dependent friction (RSF), conclusively documented in laboratory experiments and used to reproduce, both qualitatively and quantitatively, a number of earthquake-source observations (Dieterich 1979; Dieterich et al. 1981; Ruina 1983; Marone 1998; Blanpied et al. 1991; Tullis 1996; Dieterich 2007, and references therein). Such laws express the dependence of frictional shear strength $\tau_{y}$ on the confining pressure $p$ and on steady-state friction $f_{*}$ at the reference slip rate $V_{0}$, which depends on sliding velocity $V(t)$ and state variable $\theta(t)$, with the latter obeying a state evolution equation. Notably, in our continuum approach physical quantities are invariant of the coordinate system, which allows the solution to adapt to spontaneous bulk evolution. As such, our approach contains an invariant reformulation of the regularized version of RSF (Nakatani 2001; Herrendörfer et al. 2018)

$\tau_{y}=\tau_{\mathrm{II}}=a p \operatorname{arcsinh}\left[\frac{V(t)}{2 V_{0}} \exp \left(\frac{f_{*}+b \ln \left(\frac{\theta(t) V_{0}}{D_{R S}}\right)}{a}\right)\right]+\frac{\mu}{2 c_{s}} V(t)$,

where the invariant shear resistance $\left(\tau_{y}\right)$ depends on the slip rate $V(t)$, the effective confining pressure $p$, the characteristic slip distance $D_{R S}$, the rate-and-state parameters $a, b$, and the state variable $\theta(t)$. Note that eq. (14) imposes that $\tau_{y}=\tau_{\text {II }}$; hence, the yielding condition is always 
fulfilled and some plastic deformation always occurs. This way some slip always occurs if shear stress is larger than zero. Compared to the classical formulation of rate-and-state friction (e.g. Lapusta et al. 2000), our invariant formulation replaces the effective normal stress $\bar{\sigma}_{n}$ with the effective confining pressure $p$, and the shear traction $\tau$ with the shear strength $\tau_{y}$.

The slip rate $V(t)$ is computed as the magnitude of the second invariant of deviatoric plastic strain rate $\dot{\varepsilon}_{\text {II(p) }}$ over the thickness of the fault zone $W_{z}$

$V(t, x)=2 \dot{\varepsilon}_{\mathrm{II}(\mathrm{p})}^{\prime} W_{z}$.

The state variable $\theta$ describes the evolutionary effects in response to changing slip rates

$\frac{\mathrm{d} \theta}{\mathrm{d} t}=1-\frac{V \theta}{D_{R S}}$.

This state evolution law, commonly referred to as the Dieterich-Ruina or aging law, has experimental support (Beeler et al. 1996) and partial theoretical justification (Rice et al. 2001). Other formulations for the evolution of the state variable exist, such as the slip law (Ruina 1983 ) as well as various composite laws, and the formulation that best describes various laboratory experiments remains a topic of ongoing research (Bhattacharya et al. 2017). The last term in eq. (14), $\left(\mu / 2 c_{s}\right) \cdot V(t)$, represents the radiation damping term (Rice 1993; Cochard \& Madariaga 1996), which depends on the shear modulus $(\mu)$ and the shear wave speed $\left(c_{s}\right)$ of the medium where the fault is embedded. The radiation damping term is exclusively used in eq. (14) only when inertia is not solved in eq. (A4) (i.e. QD formulation). From a physical point of view, the radiation damping approximation is used to mimic the energy lost due to seismic-wave propagation (e.g. Crupi \& Bizzarri 2013).

For a constant slip velocity $V(t)$, the state variable $\theta$ evolves to its steady-state value $\theta_{s s}=L / V(t)$, transforming the shear strength $\tau_{y}$ into its steady-state form

$\tau_{s s}=p\left[f_{*}+(a-b) \ln \frac{V(t)}{V_{0}}\right]$.

Eq. (17) highlights the importance of the non-dimensional parameter $(a-b)$ for the rate dependence of friction; stable slip results for velocity-strengthening (VS) friction, $(a-b)>0$, and conditionally unstable slip for velocity-weakening (VW) friction, $(a-b)<0$ (Rice \& Ruina 1983; Scholz 1998).

In this study, we assume the dilation angle to be zero, which implies that the volume does not change during plastic yielding. Accordingly, the deviatoric plastic strain is defined as

$\left[\dot{\varepsilon}_{i j}^{\prime}\right]_{\text {plastic }}=\chi \frac{\partial \tau_{i j}}{2 \partial \tau_{\mathrm{II}}}$,

with $\chi$ being the plastic multiplier, which serves as variable scaling coefficient to ensure that the deviatoric stress always satisfies the yield criteria $\left(\tau_{\mathrm{II}}=\tau_{y}\right)$, and it is equal to the double of the square root of the second invariant of the deviatoric plastic strain rate tensor $\left(\chi=2 \dot{\varepsilon}_{\mathrm{II}(\mathrm{p})}\right)$ (Gerya 2019).

The deviatoric components $\left(\tau_{i j}\right)$ of the stress tensor $\underline{\underline{\sigma}}$ in eq. (A4) are obtained from the visco-elasto-plastic constitutive relationships (eq. 8) by using an implicit first-order finite-difference scheme in time in order to represent objective time derivatives of viscoelastic stresses (e.g. Moresi et al. 2003)

$\tau_{i j}=2 \eta_{\mathrm{vp}} Z \dot{\varepsilon}_{i j}^{\prime}+\tau_{i j}^{0} \cdot(1-Z)$,

where $Z$ is the viscoelasticity factor (Schmalholz et al. 2001)

$Z=\frac{\mu \Delta t}{\mu \Delta t+\eta_{\mathrm{vp}}}$

and $\eta_{\mathrm{vp}}$ is the effective viscoplastic viscosity that characterizes the combined viscoplastic deformation:

$\eta_{\mathrm{vp}}=\eta_{\mathrm{eff}} \frac{\tau_{\mathrm{II}}}{2 \eta_{\mathrm{eff}} \dot{\varepsilon}_{\mathrm{II}(\mathrm{p})}+\tau_{\mathrm{II}}}$,

where $\dot{\varepsilon}_{\mathrm{II}(\mathrm{p})}$ is the square root of the second invariant of the deviatoric plastic strain rate tensor.

\subsection{Adaptive time-stepping}

To resolve different timescales — ranging from long-term (slow) deformation to periodic (fast) slip events—a variable time stepping is required during computation. We use the approach of Lapusta et al. (2000), with a variable time step $(\Delta t)$ chosen as

$\Delta t=\max \left[\Delta t_{\min }, \Delta t_{\mathrm{dyn}}\right]$,

where $\Delta t_{\min }$ is the minimum time step to resolve dynamic rupture propagation, whereas $\Delta t_{\text {dyn }}$ is the dynamic time step, which varies with slip velocity. The minimum time step is given by

$\Delta t_{\min }=\gamma \Delta_{x} / c_{s}$, 
where $\gamma=1 / 4$ is a constant suggested by dynamic rupture simulations (Day et al. 2005), $\Delta_{x}$ is the minimum grid size. The dynamic time step $\Delta t_{\text {dyn }}$ is set to be inversely proportional to the maximum slip velocity $\left(V_{\max }\right)$ :

$\Delta t_{\mathrm{dyn}}=\Delta \theta_{\max } \frac{D_{R S}}{V_{\max }}$,

where the coefficient $\Delta \theta_{\max }$ is determined in Lapusta et al. (2000) by first computing a prescribed parameter that depends on the RSF parameters and the grid size

$\xi=\frac{1}{4}\left[\frac{K D_{R S}}{a P}-\frac{b-a}{a}\right]^{2}-\frac{K D_{R S}}{a p}$,

with $K=\frac{2}{\pi} \frac{\mu^{*}}{\Delta_{x}}$ defining the stiffness (assuming that slip is homogeneous throughout a single cell), and with the shear modulus $\mu^{*}=\mu /(1-$ $v)$, where $v$ is the Poisson's ratio. Accordingly

$\Delta \theta_{\max }= \begin{cases}\min \left[\frac{a p}{K D_{R S}-(b-a) p}, 0.2\right] & \rightarrow \xi>0 \\ \min \left[1-\frac{(b-a) p}{K D_{R S}}, 0.2\right] & \rightarrow \xi<0 .\end{cases}$

Following Lapusta \& Liu (2009), $\Delta \theta_{\max }$ is not allowed to be larger than 0.2. As the result of this adaptive time-stepping, large time-steps (years) are used in the interseismic period, while small time-steps (fraction of a second) are used to capture the evolution of each dynamic rupture. Note that the stability of this adaptive time-stepping procedure relies on the presence of the positive direct effect ( $a>0$ ) in the RSF formulation (eq. 14).

\subsection{Model of a subduction megathrust}

To study the behaviour of a generic subduction megathrust (Fig. 1a), we design a simple and computationally efficient setup that mimics a subduction zone in which a slab subducts beneath a continental plate (Fig. 1a). We consider a 2-D, plane-strain model, with a 1-D fault embedded in a 2-D isotropic, visco-elasto-plastic medium (Fig. 1b). This model setup assumes a megathrust interface represented as a finite-width fault zone. In order to promote depth dependency of the physical parameters, gravity acceleration $(g)$ is applied with a slab dip angle of $10^{\circ}$ (Fig. 1b).

A key element in models of sequences of earthquakes and aseismic slip is the spatial distribution of the rate-and-state dependency of friction $(a-b)$ (Fig. 1c). To allow for seismic slip, we consider a segment with steady-state velocity-weakening properties surrounded by an updip and downdip VS regions. To avoid the formation of splay-faults and allow the comparison of our modelling results with outputs from other models, we assume velocity-neutral frictional behaviour within the wedge. We then relax this assumption to assess the impact of splay-faults when they are allowed to form. The seismogenic zone incorporates gradual variations of rate and state parameters near the trench $(12<x<8 \mathrm{~km})$, and in the downdip region of the seismogenic zone $(62<x<58 \mathrm{~km})$. The length of the seismogenic segment $\left(x_{2}\right.$ $-x_{1}$, Fig. 1c) is $50 \mathrm{~km}$. In the downdip region $(x>62 \mathrm{~km})$, the VS properties of the fault allow the megathrust to slip at a rate similar or equal to plate rate. While the depth distributions of rate and state parameters assumes constant $a$ and $L, b$ increases with depth resulting in a transition to stable steady-state sliding. Pressure $(p)$, which plays the role of the normal traction on the fault interface $\left(\sigma_{n}\right)$, is set to $30 \mathrm{MPa}$. The constant value of $p$ close to the free surface is chosen for numerical tractability (Lapusta \& Liu 2009), and to investigate several issues unrelated to the free surface, such as interaction of rupture with stress heterogeneities over several earthquake sequences. Model parameters are given in Tables 1 and 2 .

\subsection{Initial and boundary conditions}

The system of equations has a unique solution given appropriate boundary conditions for the velocity and pressure (Fig. 1b). All initial unknowns in eq. (A1) and eq. (A4) are set to zero and they evolve as a result of the boundary conditions. The applied velocity boundary conditions resemble those of an analog sandbox model. For the specifics of the model setup presented in this study, the conditions on the left $(x=0)$, right $\left(x=L_{x}\right)$ and upper boundaries $(y=0)$ are defined free slip as follow:

$$
\begin{aligned}
& \frac{\partial v_{y}}{\partial x}=\left.0\right|_{x=0}, v_{x}=0 ; \\
& \frac{\partial v_{y}}{\partial x}=\left.0\right|_{x=L_{x}}, v_{x}=0 ; \\
& \frac{\partial v_{x}}{\partial y}=\left.0\right|_{y=0}, v_{y}=0 .
\end{aligned}
$$

A free slip condition requires that the normal velocity component on the boundary is zero and the other component do not change across the boundary. On the other hand, the fault and the wedge are loaded from the lower boundary $\left(y=L_{y}\right)$ by applying Dirichlet boundary conditions for horizontal velocity $v_{x}$ and zero velocity on the vertical component $v_{y}$ (Fig. 1b):

$v_{x}=\left.V_{\mathrm{pl}}\right|_{y=L_{y}}, \quad v_{y}=\left.0\right|_{y=L_{y}}$, 
(a)
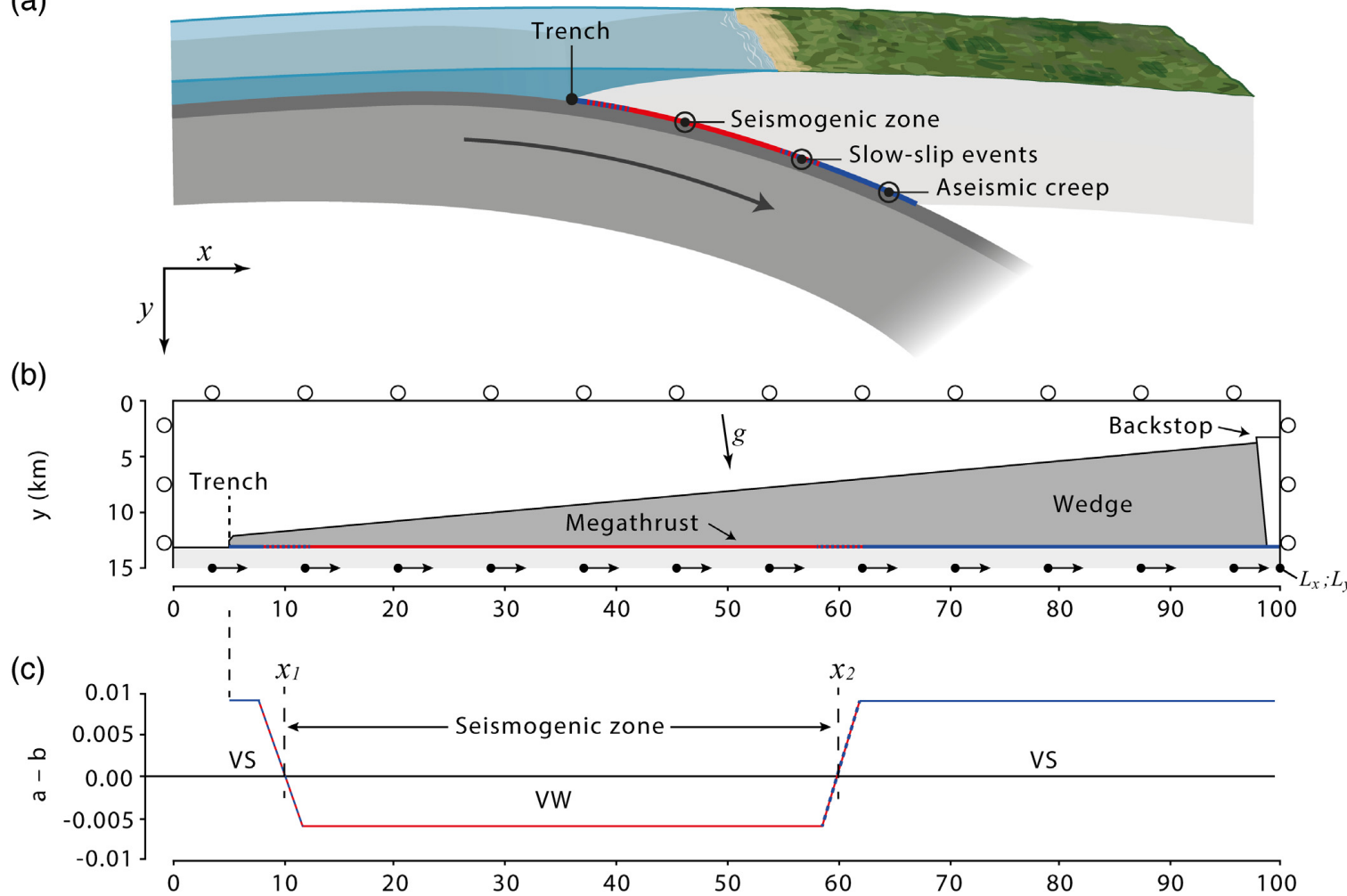

(d)

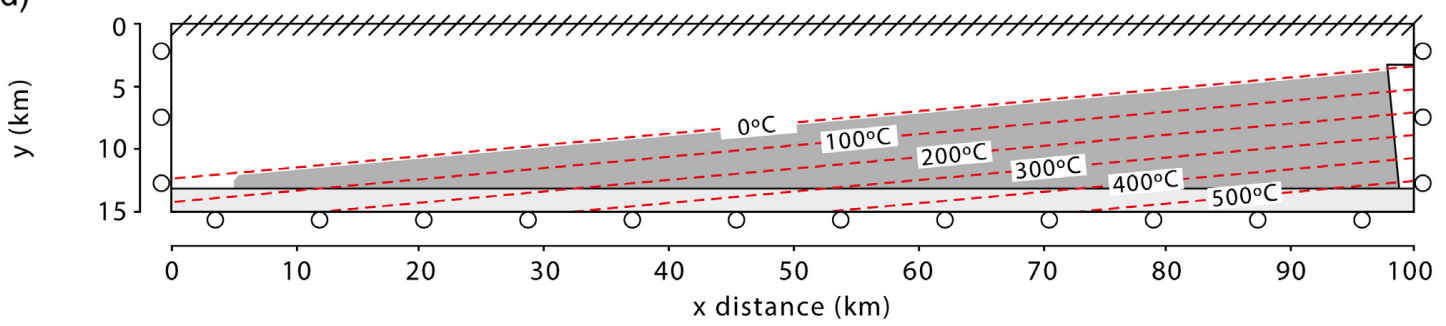

Figure 1. Schematic cross-section of a subduction zone and 2-D model setup. (a) Sketch of a generic subduction zone showing various types of slip phenomena on the megathrust interface. (b) Model setup of a simplified subduction zone with a planar megathrust embedded in homogeneous visco-elasto-plastic medium. Boundary conditions include: free slip (small rollers) at the top, left, and right boundaries, whereas tangential displacement (small arrows) is prescribed at the bottom boundary. (c) Rate-and-state frictional properties of the simulated fault segment. The seismogenic region with velocity-weakening properties (shown in red) is surrounded by velocity-strengthening regions (shown in blue). (d) Temperature structure used for the simulations with power-law rheology. Red dashed lines indicate the isotherms. Thermal boundary conditions include: insulating boundary conditions (i.e. zero heat flux) at the left, right and lower boundaries, whereas constant temperature condition is imposed at the top boundary (black diagonal lines).

Table 1. Model parameters.

\begin{tabular}{lcl}
\hline Parameter & Symbol & \multicolumn{1}{c}{ Value } \\
\hline Shear modulus & $\mu$ & $30 \mathrm{GPa}$ \\
Bulk modulus & $K$ & $50 \mathrm{GPa}$ \\
Poisson ratio & $v$ & 0.25 \\
Confining pressure & $p$ & $30 \mathrm{MPa}$ \\
Density & $\rho$ & $2700 \mathrm{~kg} \mathrm{~m}^{-3}$ \\
Shear wave speed & $c_{S}$ & $3333 \mathrm{~m} \mathrm{~s}^{-1}$ \\
Fault width & $W_{z}$ & $20 \mathrm{~m}$ \\
Gravity & $g$ & $9.81998 \mathrm{~m} \mathrm{~s}^{2}$ \\
Reference friction & $f_{*}$ & 0.6 \\
Characteristic slip distance & $D_{R S}$ & $0.014 \mathrm{~m}^{-}$ \\
RSF direct effect & $a$ & 0.010 \\
RSF evolution effect & $b$ & 0.017 \\
RSF initial state variable: & $\theta_{i}$ & \\
- bulk & & $D_{R S} / V_{0} \exp (20)$ \\
- fault & & $D_{R S} / V_{0} \exp (-1)$ \\
Critical nucleation size & $h^{*}$ & $8.2 \mathrm{~km}$ \\
Cohesive zone size & $\Lambda_{0}$ & $970 \mathrm{~m}$ \\
Reference velocity & $V_{0}$ & $10^{-6} \mathrm{~m} \mathrm{~s}_{-}{ }^{1}$ \\
Loading velocity (plate rate) & $V_{p}$ & $2 \times 10^{-9} \mathrm{~m} \mathrm{~s}^{-}{ }^{1}$ \\
\hline
\end{tabular}


Table 2. Values used for power-law flow parameters. $\rho_{0}$ is the reference density, $k$ is the thermal conductivity, $A_{d}$ is the pre-exponential factor, $E_{a}$ is the activation energy, $V_{a}$ is the activation volume, $n$ is the stress exponent, $\eta_{0}$ is the reference viscosity.

\begin{tabular}{lcccccr}
\hline Material & $\begin{array}{c}\rho_{0} \\
{\left[\mathrm{~kg} \mathrm{~m}^{-3}\right]}\end{array}$ & $\begin{array}{c}k \\
{\left[\mathrm{~W} \mathrm{~m}^{-1} \mathrm{~K}^{-1}\right]}\end{array}$ & $\begin{array}{c}A_{d} \\
{\left[\mathrm{MPa}^{-n} \mathrm{~s}^{-1}\right]}\end{array}$ & $\begin{array}{c}E_{a} \\
{\left[\mathrm{~kJ} \mathrm{~mol}^{-1}\right]}\end{array}$ & $\begin{array}{c}V_{a} \\
{\left[\mathrm{~J} \mathrm{bar}^{-1} \mathrm{~mol}^{-1}\right]}\end{array}$ & $\begin{array}{c}n \\
{\left[\mathrm{~Pa}^{n} \mathrm{~s}\right]}\end{array}$ \\
\hline Wedge (wet quartzite) $^{a}$ & 2700 & {$[0.64+807 /(T+77)] \exp \left(4 \times 10^{-5} p\right)$} & $3.2 \times 10^{-4}$ & 154 & 0.8 & 2.3 \\
Slab (plagioclase An75) $^{\mathrm{a}}$ & 2700 & {$[1.18+474 /(T+77)] \exp \left(4 \times 10^{-5} p\right)$} & $3.3 \times 10^{-4}$ & 238 & $1.97 \times 10^{17}$ \\
\hline
\end{tabular}

${ }^{\mathrm{a}}$ Ranalli (1995).

where $V_{\mathrm{pl}}=6.3 \mathrm{~cm} \mathrm{yr}^{-1}$ corresponds to the long-term loading rate.

In order to predict the evolution of temperature due to heat transport, the heat conservation equation (eq. A5) is solved. This equation describes the balance of heat in a continuum and relates temperature changes to heat advection and conduction (Gerya 2019). Since heat advection is considered negligible at the timescales of our problem, we first define an initial temperature structure (Fig. 1d). The initial temperature structure mimic a linear gradient across the megathrust, in which the temperature increases from 0 to $600{ }^{\circ} \mathrm{C}$. Following the initial temperature structure, we specify the thermal boundary conditions (Fig. 1d). These are set to constant temperature condition (i.e. $0{ }^{\circ} \mathrm{C}$ ) at the top boundary, whereas insulating boundary conditions (i.e. zero heat flux) is imposed at the left, right and lower boundaries as follow:

$\left.\frac{\partial T}{\partial x}\right|_{x=0}=\left.\frac{\partial T}{\partial x}\right|_{x=L_{x}}=\left.\frac{\partial T}{\partial y}\right|_{y=L_{y}}=0$.

In order to ensure a low thermal gradient along the free surface, we assume high thermal conductivity in the air.

Since the conservation of mass (eq. A1) does not contain any dependence on the pressure and the momentum equation (eq. A4) contains $\nabla p$, the pressure has to be initialized only at one of the internal pressure nodes (typically the leftmost top inner node). This condition is strongly enforced via

$p=\left.p_{0}\right|_{x=1, y=1}$

where the initial pressure $\left(p_{0}=0 \mathrm{~Pa}\right)$ is defined. This allows the absolute pressure values to be defined through the pressure gradients present in the momentum equations (Gerya 2019).

\subsection{Spatial discretization}

We adopt a 2-D, staggered-grid finite difference (stag-FD) method, in which the grid is comprised of quadrilaterals cells parallel to the underlying coordinate basis vectors (Gerya \& Yuen 2007). The numerical method is developed for an in-plane problem using a fully staggered grid, which means that physical variables (pressure, velocities, and stresses) are defined at different geometric points. The system of equations is implicitly solved for velocities and pressure using the direct inversion method based on the Pardiso solver (Schenk \& Gärtner 2004). An essential modelling requirement when studying long-term geological processes is the ability to model multiple rock types and to permit these rocks to undergo large deformation, as it often occurs within geodynamic scenarios. To do so, the Eulerian spatial discretization is combined with a Lagrangian marker-in-cell advection scheme (Gerya \& Yuen 2007). A set of Lagrangian particles (or material points) advects through the Eulerian domain used to discretize the velocity, pressure and temperature field. The Lagrangian particles have no assumed connectivity with each other and, as a consequence, large strain and advection of the continuum can be sustained. The Lagrangian particles are used to assign rock properties (e.g. density, viscosity, shear modulus and RSF properties), and, during the simulation, they store deviatoric stresses, pressure, velocities and state for evaluating the respective time derivatives. A standard distance-dependent bi-linear interpolation scheme is used to interpolate physical parameters from the Lagrangian markers to the staggered Eulerian nodes at the beginning of each time step and update marker values at the end of each time step.

\subsection{Physical length scales to resolve nucleation and rupture propagation}

Three important physical scales to consider for the spatial discretization of this problem are (1) the nucleation size $h^{*}$, (2) the cohesive zone size $\Lambda$ and (3) the fault thickness $W_{z}$. The nucleation size is a crucial length scale during interseismic periods and $h^{*} / \Delta x$ is an important criterion to assess spatial resolution. For 2-D problems with velocity-weakening rate-and-state friction, two theoretical estimates of the earthquake nucleation size are $h_{r r}^{*}$ (Rice \& Ruina 1983) and $h_{r a}^{*}$ (Rubin \& Ampuero 2005):

$h_{r r}^{*}=\frac{\pi}{4} \frac{\mu^{*} D_{R S}}{p(b-a)}$

$h_{r a}^{*}=\frac{2}{\pi} \frac{\mu^{*} D_{R S} b}{p(b-a)^{2}}$

where $v$ is the Poisson's ratio, and the estimate eq. (32) is valid for $0.5<a / b<1$, as explained in Rubin $\&$ Ampuero (2005). $h_{r r}^{*}$ was derived from the linear stability analysis of steady sliding, whereas $h_{r a}^{*}$ was obtained using the energy balance for a quasi-statically extending crack 
for the parameter regime $a / b>0.5$. In the parameter regime $0<a / b<0.3781$, Rubin \& Ampuero (2005) advocated $b$ instead of $(b-a)^{2} / b$ in eq. (32); however, $(b-a)^{2} / b \rightarrow b$ as $a \rightarrow 0$, so that eq. (32) should approximately capture both cases. Given the parameters used (see Table 1), the theoretically estimated nucleation sizes in our models are $2.1 \mathrm{~km}$ based on eq. (31), and $4.1 \mathrm{~km}$ based on eq. (32). However, since the fault thickness is two times the grid size $(\Delta y)$, our models display a factor 2 difference between the theoretical estimation of the nucleation size and its actual size. The chosen values of $D_{R S}$ are larger than those obtained in laboratory, which facilitate our numerical computation (Lapusta \& Liu 2009).

The second important physical scale to consider, the cohesive zone size $\Lambda$, is important in dynamic rupture and hence $\Lambda / \Delta x$ is another resolution criterion (Palmer \& Rice 1973; Day et al. 2005). For rate-and-state friction law, $\Lambda_{0}$, the size of $\Lambda$ at the rupture speed $c=0^{+}$, is given by:

$\Lambda_{0}=C_{1} \frac{\mu D_{R S}}{b p}$,

where $C_{1}$ is a constant and equal to $9 \pi / 32$ if the stress traction distribution within the cohesive zone is linear in space. Following Day et al. (2005), we require that $\Lambda_{0} / \Delta x$ has to be more than 5 to resolve dynamic rupture. With the chosen values (see Table 1), the resulting cohesive zone size is $970 \mathrm{~m}$. We thus choose a horizontal grid resolution $(\Delta x)$ of $100 \mathrm{~m}$, which allows to resolve the evolution of stress and slip rate with at least 9 cells at the initiation of dynamic rupture when the rupture speed is close to zero; the cohesive zone size shricks as the rupture propagates. In our simulations, the decreasing cohesive zone size is resolved by at least 6 cells during dynamic propagation. The ratio between the nucleation zone size and cohesive zone size is given by $\Lambda_{0} / h_{r r}^{*} \sim(b-a)^{2} / b^{2}$ (Lapusta et al. 2000). Given $a=0.010$ and $b=$ 0.017 in our model, the ratio $\Lambda_{0} / h_{r r}^{*}$ is equal to 0.17 . This means that resolving the cohesive zone is the more stringent numerical criterion. Furthermore, the $\Lambda_{0} / h_{r r}^{*}$ suggests that resolving the cohesive zone size with more than 3-5 nodes, corresponds to resolving $h_{r r}^{*}$ with more than 20 nodes. This confirms the results of Lapusta et al. (2000), in which they suggest that $h_{r r}^{*}$ needs to be resolved with $\sim 20$ nodes in order to obtain resolution-independent results.

The third physical scale to consider is the fault thickness $W_{z}$. In our continuum model, plastic deformation is computed as volumetric strain over a finite thickness, and it is represented by a tensor. This means that plastic deformation can spontaneously localize anywhere, that is on the megathrust and in the wedge. Since plastic deformation localizes within 1-2 cells, the thickness of a fault zone depends on the grid size (De Borst \& Sluys 1991). In order to resolve a sufficiently thin fault zone, in this work we develop a variable grid spacing in the vertical direction $(\Delta y)$, which enables a maximum cell size of $200 \mathrm{~m}$ at the upper and lower boundary (far from the fault), and a minimum cell size of $20 \mathrm{~m}$ across the fault. Although the fault thickness may vary with depth (Rowe et al. 2013), and the thickness of actively sliding shear layer can be quite narrow (Rice 2006; Rice et al. 2014; Platt et al. 2014), $W_{z}$ is chosen to reflect the potential broad thickness of subduction plate boundary faults and to allow for numerical tractability.

\subsection{Adaptive free surface}

To mimic the presence of air, our continuum-based approach assumes a low viscosity and low density layer, which ensures sufficiently small shear stresses at the air/rock interface (Crameri et al. 2012). This pseudo-free surface approximation is a widely documented numerical treatment called 'sticky-air', which has been shown to be successful in obtaining geodynamic models with a realistic surface topography (Gerya 2019). This approach is typically used assuming a constant viscosity in time for steady and long-term viscoplastic processes ( $\Delta t \geq$ $1000 \mathrm{yr}$ ). However, a constant viscosity is not ideal when a fault slips coseismically at rates of the order of meters per second. Based on the approach introduced in Herrendörfer (2018), we implement an adapting viscosity of the air with the computational time step which, in turn, depends on the maximum slip rate (eq. 15). To ensure that the air behaves purely viscously, we require that the ratio of the elastic shear stress change in the host rock and the viscous shear stress in the air layer to be

$\eta_{\text {air }}=\frac{\mu \Delta t}{\varphi}$

where $\varphi$ is the adaptivity factor. The adaptivity factor has to be sufficiently high in order to avoid oscillations and problems in convergence. Numerical oscillations occur because stresses increase in the air-rock interface, thus triggering numerical instabilities. Increasing the adaptivity factor ensures that stresses on the air-rock interface remain low and that the free surface approximation is valid during the entire simulation. As the adaptive time steps $\Delta t_{\text {dyn }}$ follows eq. (24), $\eta_{\text {air }}$ is essentially governed by the maximum slip rate $V(t)$ and therefore by the maximum plastic strain rate in the model. Hence, for periods of high plastic strain rates during the rupture propagation of an earthquake, $\eta_{\text {air }}$ is adapted to low values.

\section{RESULTS}

In this section, we present simulations of sequences of seismic and aseismic slip on the simplified subduction megathrust. In Section 3.1, we assume linear viscosity and we compare quasi-dynamic (QD) and fully-dynamic (FD) simulations by exploring the long-term behaviour of rate-and-state megathrust model. In Section 3.2, we incorporate a depth-dependent temperature structure and analyse the effect of non-linear rheologies. In Section 3.3, we combine the FD simulations and thermally activated non-linear rheologies to simulate off-megathrust seismic events. 
(a) Interseismic loading
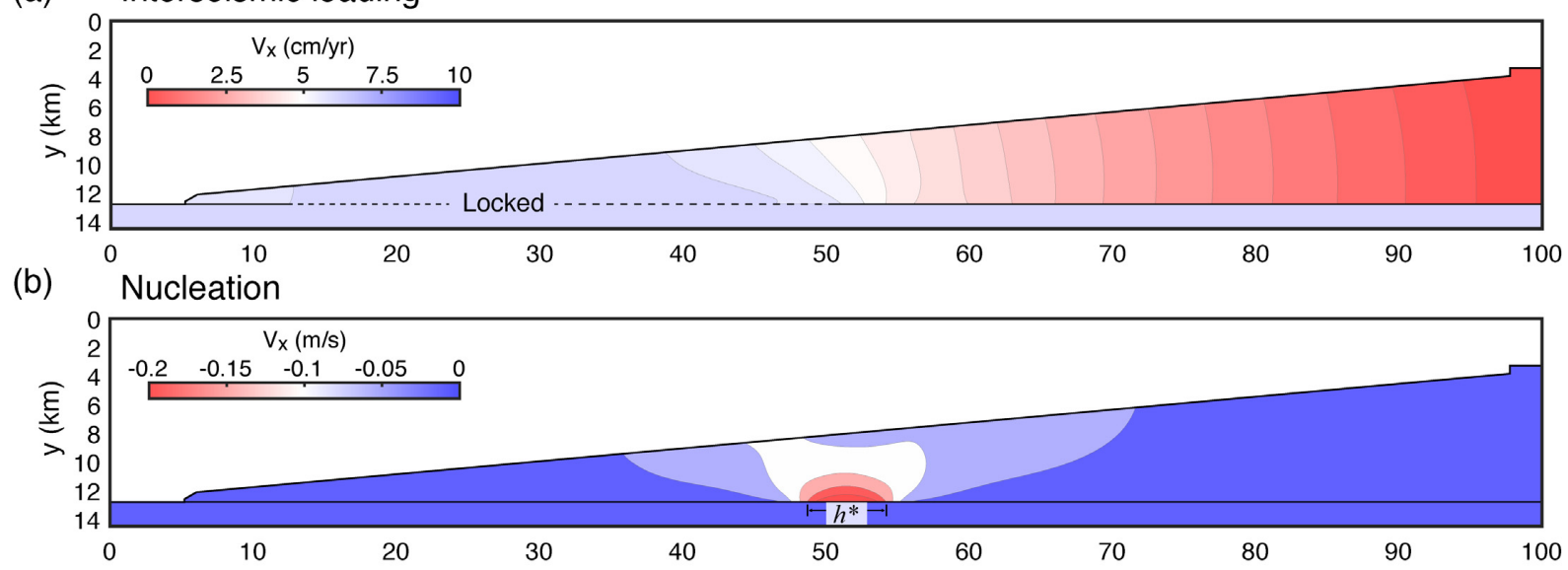

(c) Propagation

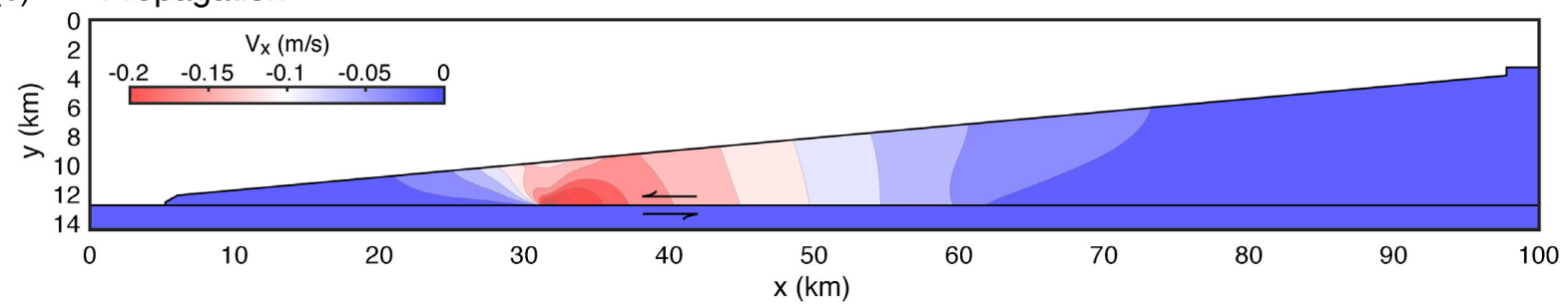

Figure 2. Snapshots of the spatial horizontal velocity $\left(v_{x}\right)$ distribution during the phases of (a) interseismic loading, (b) nucleation and (c) dynamic propagation. (a) The response of the megathrust and the wedge to tectonic loading is characterized by long interseismic periods of quasi-static deformation, in which the shallow portion of the megathrust $(x<60 \mathrm{~km})$ is practically locked, with similar particle velocities above and below the megathrust, whereas deeper (velocitystrengthening) fault zone steadily creeps at rates comparable to the plate convergence rate. (b) Earthquakes nucleate at the lower edge of the locked portion. (c) Slip instability results in a dynamic rupture that typically propagates first bilaterally and then mainly updip. Note that the colour scale of velocities in (a) differs significantly from the one in (b) and (c).

\subsection{Quasi-dynamic (QD) versus fully-dynamic (FD) simulations}

The response of the megathrust and the wedge to tectonic loading is characterized by long periods of quasi-static deformation followed by short, and fast, slip events (Figs $2 \mathrm{a}-\mathrm{c}$ ). Since the time step is set to be inversely proportional to slip velocity (eq. 24), relatively large time steps - of the order of a fraction of a year - are used in the interseismic period, while small time steps of the order of milliseconds are used to simulate the evolution of each dynamic rupture (Figs $3 a$ and $b$ ).

Despite the relatively simple model setup, a complex fault behaviour arises from the numerical experiments, including partial and complete ruptures of the seismogenic zone, as well as aseismic slip transients (Figs $3 \mathrm{c}$ and d). In the early stages of the simulations, the imposed loading rate increases stress linearly with time, whereas slip rate increases exponentially with time in the VS fault zone. While the VS fault zone steadily creeps at rates comparable to the plate convergence rate (Figs $3 \mathrm{c}$ and d), the VW fault segment remains locked during interseismic periods and slips mainly when an event, either fast or slow, occur. During the interseismic periods, creep penetrates from the VS region to the seismogenic zone, leading to a mechanical erosion of the lower edge of the locked patch, while stress concentrates at the rheological transition ( $c f$. Lapusta et al. 2000; Bruhat \& Segall 2017). The later stages of the interseismic periods contain slip episodes faster than the plate rate, that is aseismic slip transients or slow-slip events, which often precede the nucleation of seismic events. These transients, which have a maximum slip velocity of about $10^{-7} \mathrm{~m} \mathrm{~s}^{-1}$, develop in the downdip region of the VW fault zone, close to rheological transitions and constitute propagating nucleation attempts. When a seismic event nucleates, the resulting dynamic rupture typically propagates in an asymmetric fashion, that is bilaterally first and then mainly updip.

Overall, FD and QD simulations display some qualitative similarity, yet substantially different from a quantitative point of view, as demonstrated in previous studies (Lapusta et al. 2000; Lapusta \& Liu 2009). Both the maximum rupture speed and slip rate during dynamic ruptures is lower for the QD simulation than for the FD one (Figs 3a, b and 4). In particular, the average slip rate is 0.94 and $1.42 \mathrm{~m} \mathrm{~s}^{-1}$ for QD and FD simulations, respectively, whereas the average rupture speed indicates that QD events propagate at $\sim 2.41 \mathrm{~km} \mathrm{~s}{ }^{-1}$ and FD events at $\sim 2.60 \mathrm{~km} \mathrm{~s}^{-1}$. Furthermore, the spatiotemporal evolution of slip rate is significantly different between the two models: while the QD simulation results in a variable pattern of partial and complete ruptures, the FD simulation is predominantly dominated by complete ruptures (cf. Figs 3c and d). Evolution of the cumulative slip on both QD and FD simulations over multiple earthquakes are displayed in Fig. 4, with the accumulation of slip on the megathrust during interseismic periods represented by gray lines plotted every $10 \mathrm{yr}$, whereas red lines display cumulative slip every $1 \mathrm{~s}$ when the maximum slip velocity on the fault exceeds the commonly used velocity threshold defined by Rubin \& 
(a)

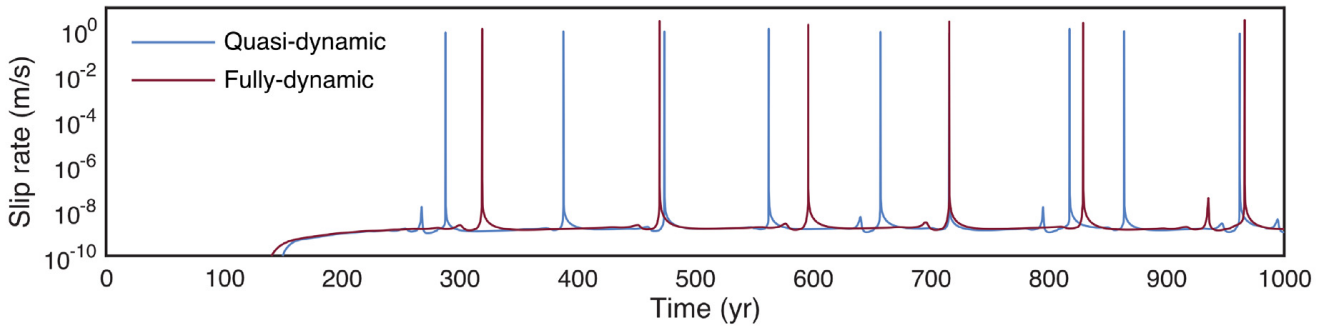

(b)

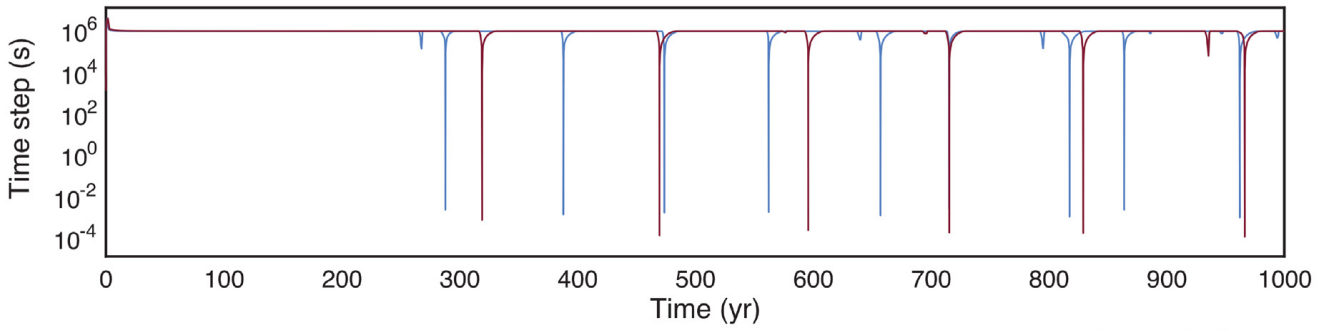

(c)

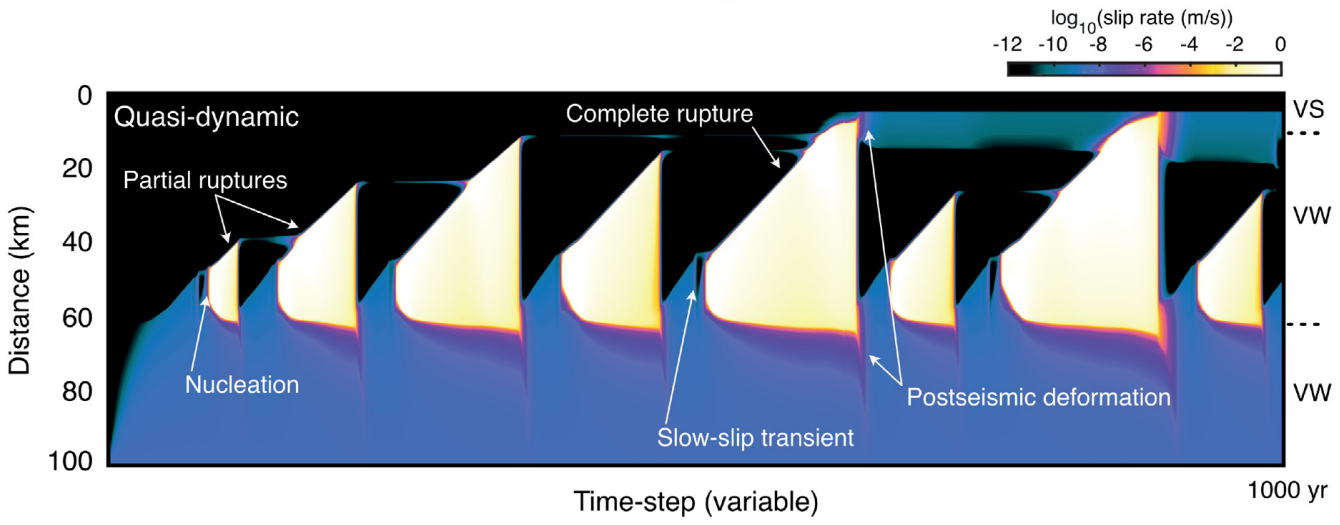

(d)

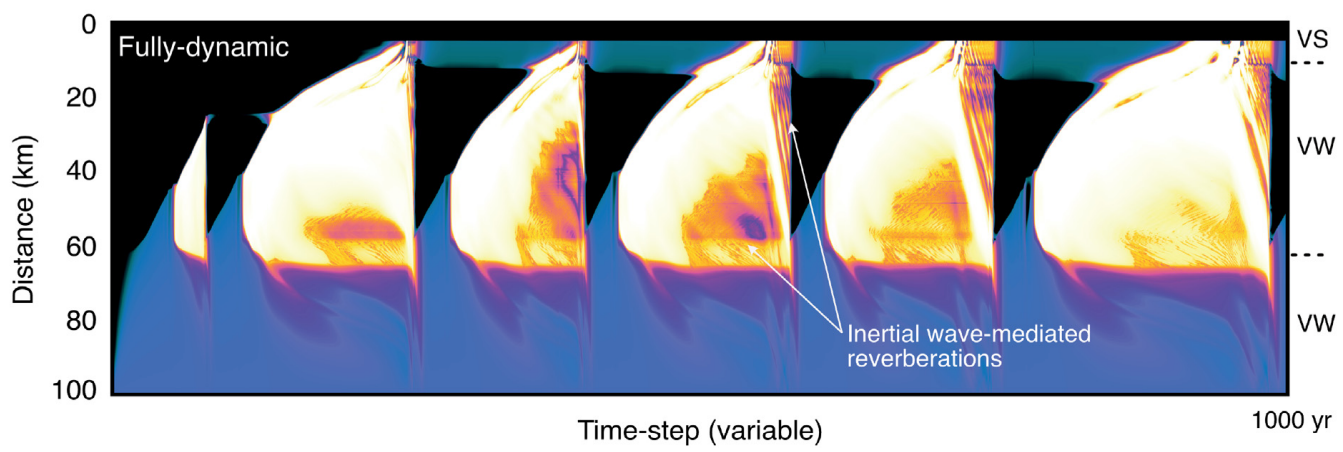

Figure 3. Overview of the results for the quasi-dynamic and fully dynamic reference models. Temporal evolution of (a) maximum slip velocity and (b) minimum time-step. The time step is set to be inversely proportional to slip velocity, which results in large time steps in the interseismic periods, and small time steps (of the order of milliseconds) to simulate the evolution of each dynamic rupture. Long-term histories of slip rate on the megathrust for the (c) quasi-dynamic and (d) fully dynamic reference models. Note that, in order to visualize the evolution of dynamic ruptures, the $x$-axis displays the time step. In both models, the simulation periods are $1000 \mathrm{yr}$, which start with a $\sim 250 \mathrm{yr}$ spin-up period. Slip velocity is plotted on the logarithmic scale.

Ampuero (2005):

$V_{\mathrm{th}}=\frac{2 a p c_{s}}{\mu}$

Based on our parameters, $V_{\mathrm{th}}=0.067 \mathrm{~m} \mathrm{~s}^{-1}$. The average cumulative slip for a representative dynamic rupture is larger for the FD simulation.

These differences, which have already been pointed out in previous studies (Lapusta \& Liu 2009; Thomas et al. 2014), occur because wave-mediated stress transfers significantly affect the model response, producing larger stress drop and coseismic slip. As a result, fewer events are necessary in the FD simulation to achieve the same amount of cumulate slip compared to the QD simulation ( $c f$. Figs $4 \mathrm{e}$ and $\mathrm{f}$ ). These results indicate that wave-mediated stress transfers play a key role in rupture propagation, creating more favourable stress conditions for dynamic rupture to propagate through unfavorable patches (e.g. Kaneko et al. 2010), or potentially to transition to supershear speeds (e.g. Dunham et al. 2003). Thus, our calculations appear to correctly account for the effect of wave-mediated dynamic stresses on seismic rupture 
(a)

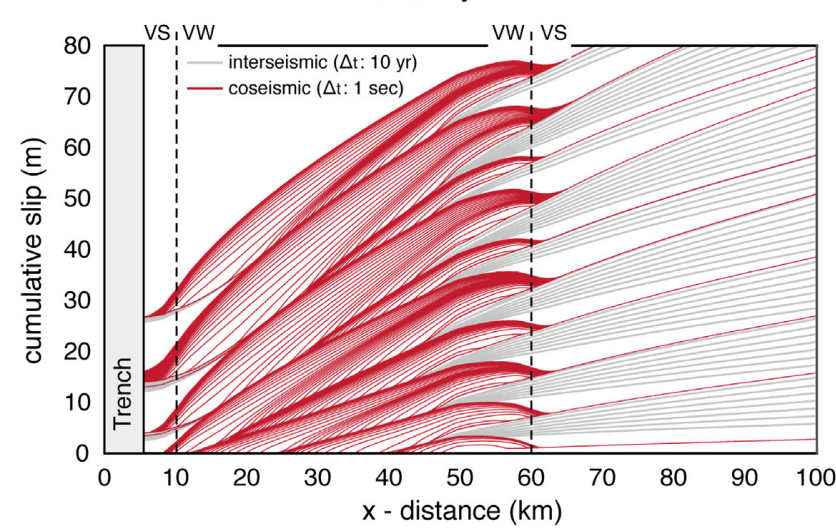

(b)

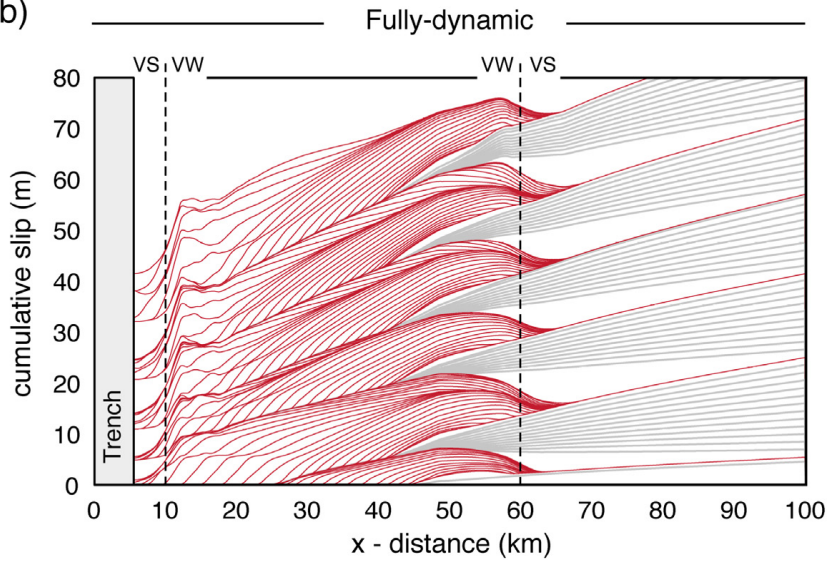

Figure 4. Cumulative slip on the megathrust for (a) quasi-dynamic (QD) and (b) fully dynamic (FD) simulations with the rate-and-state friction law and linear viscosity. The cumulative slip is plotted on the megathrust after multiple events. Red lines indicate the coseismic slip every $1 \mathrm{~s}$ when the maximum slip velocity exceeds the threshold of $0.067 \mathrm{~m} \mathrm{~s}^{-1}$ (see eq. 35), while gray lines (every $10 \mathrm{yr}$ ) illustrate the interseismic (aseismic) behaviour of the fault. Overall, FD simulations display higher rupture speeds (larger spacing between red lines) and larger slip per event than quasi-dynamic simulations.

propagation. Shear waves in FD simulations propagate from the fault through the computational domain and bounce back at the free surface, thus producing a reverberation phase in the later stages of dynamic ruptures (Fig. 3d). Fault slip and ground motions are particularly sensitive to the fault depth, with larger amplitudes close to the trench, indicating strong effects of the wave reverberation between the fault and the free surface.

To compare the stress variations in the QD and FD simulations, we analyse the evolution of the average shear stress and the averate state variable on the fault defined as:

$$
\begin{aligned}
\tau_{a v} & =\frac{1}{x_{2}-x_{1}} \int_{x_{1}}^{x_{2}} \tau_{y}(x, t) \mathrm{d} x, \\
\theta_{\mathrm{av}} & =\frac{1}{x_{2}-x_{1}} \int_{x_{1}}^{x_{2}} \theta(x, t) \mathrm{d} x,
\end{aligned}
$$

where $x_{1}$ and $x_{2}$ delimits the VW region at $x_{1}=10 \mathrm{~km}$ and $x_{2}=60 \mathrm{~km}$, respectively (Fig. 1c). When the fault is continuously loaded at a constant rate, the mechanical system oscillates in non-periodic cycles among shear stress (Fig. 5a) and state variable (Fig. 5b). The evolution of the average shear stress through time for QD and FD simulations display pseudo-steady interseismic accumulation of stress due to the tectonic loading, followed by abrupt transients representing a frictional instability on the fault and the occurrence of a dynamic rupture (Fig. 5a). On the other hand, the state variable stays relatively high during the interseismic periods and ultimately drops during the onset of dynamic ruptures (Fig. 5b). The maximum level of shear stress before each seismic event-representing the maximum average strength that the fault can sustain - is close to the quasi-static strength $\left(\bar{\sigma}_{n} \cdot f_{*}=18 \mathrm{MPa}\right)$. However, the FD simulation indicates lower stress levels compared to the QD simulation. This outcome is consistent with previous analysis (Thomas et al. 2014), and suggests that inertia effects from the FD simulation promote stress concentration in the frictionally unstable region and rupture propagation over regions with lower average pre-stress. Static stress drops are of the order of 2.00 and 1.60 MPa for the QD and FD, respectively, which is consistent with the observation that wave-mediated stress transfer produces large coseismic slip on the fault. Note that the average dynamic stress drops, that is the difference between the peak average stress and the residual stress, are larger, which occur as a result of the dynamic overshoot and pulse-like nature of the ruptures.

The evolution of shear stress during the phases of loading, nucleation, propagation and arrest, is described in more detail in Fig. 5(c). Overall, these results indicate a larger range of shear stress and slip velocity variations for the FD simulation compared to the QD simulation. During the loading phase, shear stress is increased, and, consequently, slip velocity also increases, yet at negligible rates. When an event nucleates, shear stress drops while slip velocity increases rapidly. Since the rupture speed at this stage is still close to zero, the length along which the stress drop occurs represents the quasi-static cohesive zone length (eq. 33). During the onset of the dynamic instability-which is modulated by the feedback between decreasing state and increasing slip velocities - shear stress drops within nucleation region, whereby the surroundings are dynamically loaded. When the event begins to propagate dynamically, it produces a shear stress breakdown from its maximum value to the dynamic level. When the rupture propagation arrests, slip rate drops several orders of magnitudes, thus promoting the healing of the state variable, which increases nearly linearly with time.

\subsection{Earthquake cycles with power-law rheology}

In this section, we present results from QD and FD visco-elasto-plastic simulations accounting for the effects of the temperature and strain rate on viscous rheology. These simulations with power-law rheology, compared to the ones of the previous section, allow for comparison with simple analytical solutions of post-seismic deformation, both afterslip and viscoelastic relaxation. In these models, the effective viscosity is 
(a)
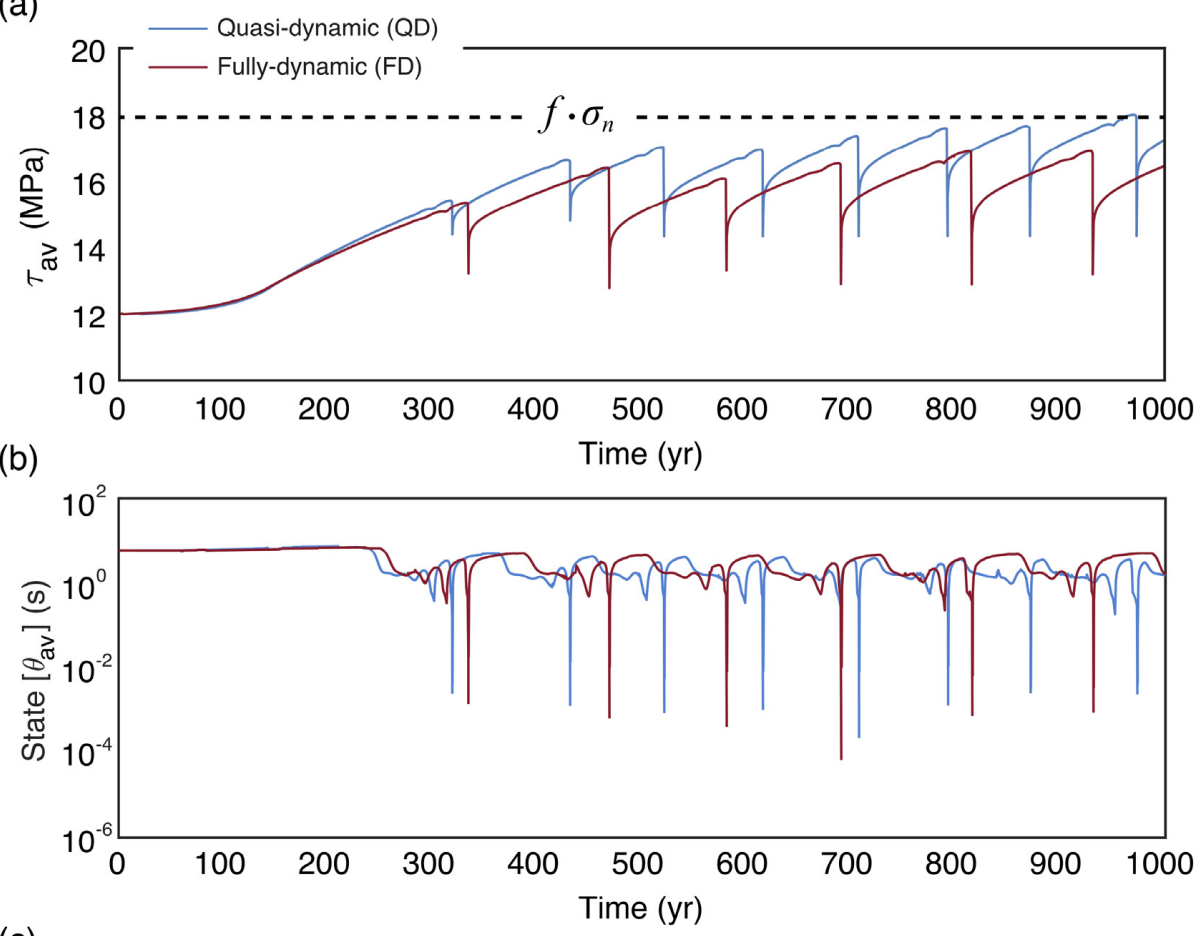

(c)

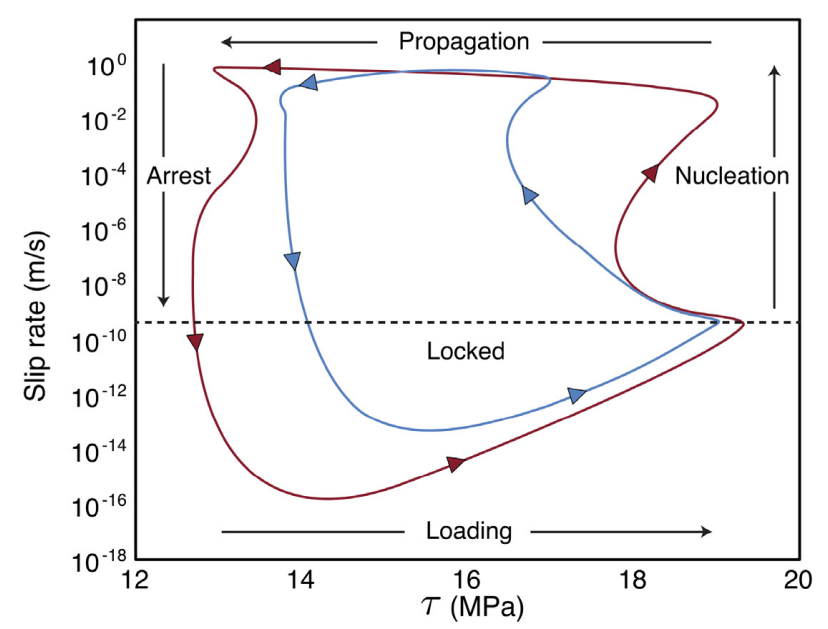

Figure 5. Shear stress evolution on the megathrust. (a) Averaged shear stress $\left(\tau_{\mathrm{av}}\right)$ and (b) averaged state $\left(\theta_{\mathrm{av}}\right)$ on the megathrust over many earthquake cycles (computed from eqs 36a to 36b). The solid blue line corresponds to the quasi-dynamic simulation, whereas the solid red line corresponds to the fully dynamic simulation. The dashed black line represents the fault-averaged quasi-static fault strength. (c) Phase diagrams of period-doubling cycles for the shear stress versus slip rate for both quasi- and fully dynamic simulations. The observational point in taken the middle of the seismogenic zone $(x=35 \mathrm{~km})$.

set by the rheology, which evolves spatially and temporally as a function of strain rate and temperature. We assume a temperature structure (Fig. 1d), and assign rheological parameters derived from laboratory experiments (Table 2). Throughout the entire wedge, temperature increases linearly from 0 to $600{ }^{\circ} \mathrm{C}$. Notably, with this temperature distribution, the $360^{\circ} \mathrm{C}$ isotherm intersects the fault at $x \sim 60 \mathrm{~km}-$ that is, where the frictional behaviour changes from VW to VS. This way, the downdip region of the megathrust experiences both frictional rate strengthening and thermally activated viscous creep (Fig. 6).

The two models (QD and FD simulations) illuminate the thermomechanical effects throughout the sequences of seismic and aseismic slip, from the interseismic periods to the nucleation phases, as well as the relation between the depth of coseismic slip and the locked-creeping transition zone. Results indicate that, during the interseismic periods, the shallow portion of the wedge $(x<60 \mathrm{~km})$ is highly elastic, with negligible viscous strain (Fig. 6). Since the temperature in the seismogenic zone is relatively low, interseismic periods on the VW fault zone are mainly controlled by the frictional parameters. Compared to the simulations with linear rheology (Section 3.1), the simulations with power-law viscosity display lower interseismic slip rates in the deeper region of the fault. This occurs because thermally activated rheology promotes bulk viscous flow over a broader shear zone. As the temperature increases with depth, the integrated effects of frictional sliding and viscous flow control the long-term tectonic loading. Thus, the cumulative contribution of fault slip and viscous strain matches the long-term 

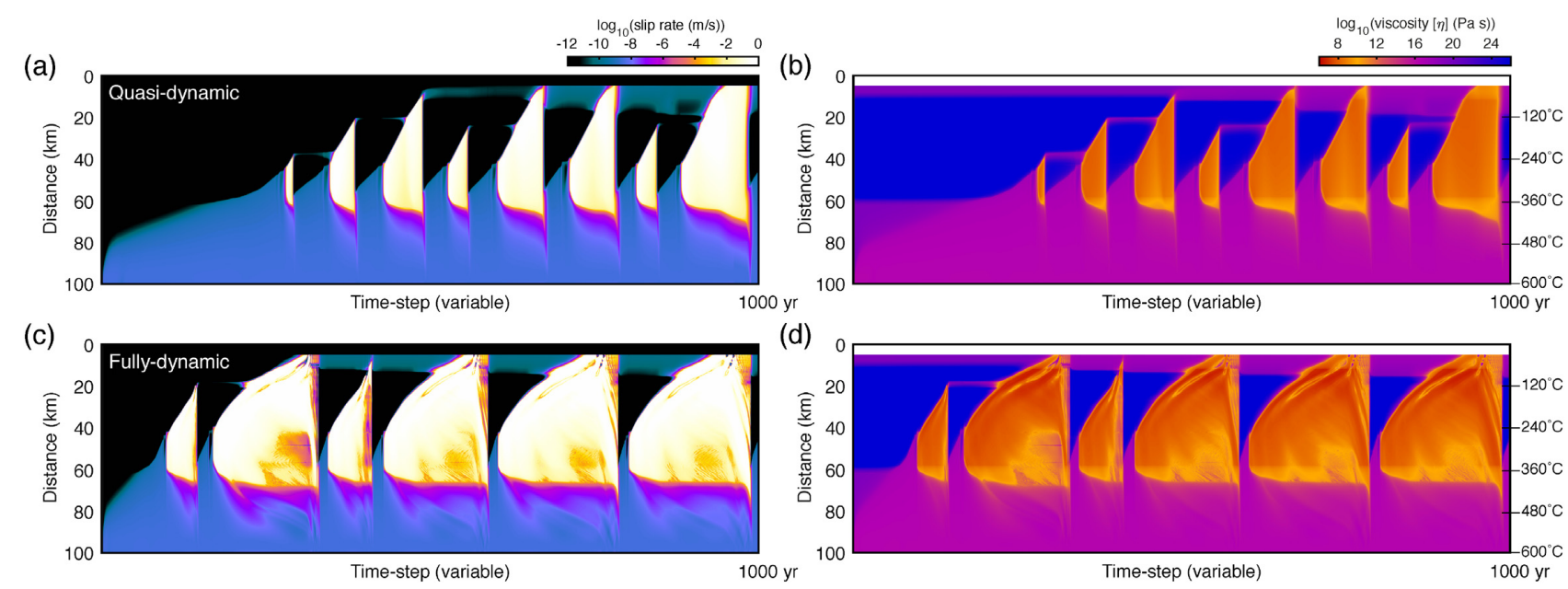

(d)

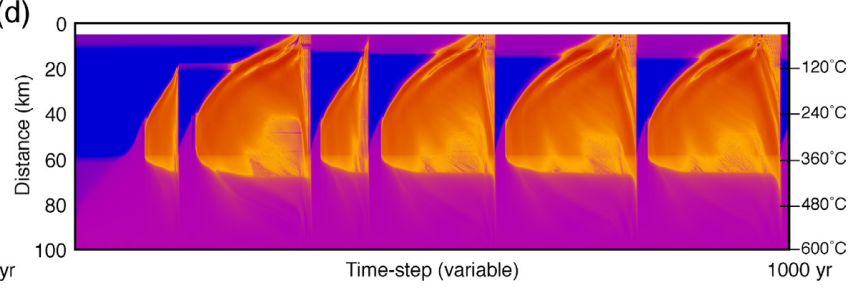

Figure 6. Long-term histories of $(a, c)$ slip rate and (b, d) viscosity on the megathrust for the quasi-dynamic and fully dynamic reference models with temperature-dependent power-law rheology. Note that, in order to visualize the evolution of dynamic ruptures, the horizontal axis of each panel displays the time step. In both models, the simulation periods are $1000 \mathrm{yr}$, which start with a $\sim 250 \mathrm{yr}$ spin-up period. Both slip velocity and viscosity are plotted on the logarithmic scale. Note that the temperature on the fault is indicated on the right vertical axis of panels (b) and (d).

tectonic loading $\left(V_{p}\right)$. The features of lower interseismic slip rate in the deeper region of the fault, the recurrence interval and the highly frictional behaviour of the seismogenic zone were already observed in simulations by Kato (2002) and Allison \& Dunham (2018).

Earthquakes nucleate at the lower edge of the locked portion of the megathrust, with a recurrence interval approximately similar to the simulations with linear rheology. The evolution of coseismic slip, however, is substantially different, with additional fault weakening at seismic slip rates (Fig. 6). The physical mechanism responsible for the additional coseismic weakening is the strong decrease in viscosity due to rapid strain-rate localization, which causes slip velocity to increase further. When the effective viscosity is sufficiently low, coseismic slip penetrates into the VS fault region, essentially activating the VS patch from being interseismically stable to coseismically unstable. As a result, the slip velocity there remains high and causes an accumulation of slip, creating a stress concentration that eventually dissipates during the post-seismic phase.

\subsection{Off-megathrust splay-fault events}

To investigate the influence that slip from megathrust earthquakes has on the spontaneous activation of splay-faults, we apply two modifications in the model setup. First, instead of assuming a velocity-neutral frictional behaviour within the wedge, we impose the same VW frictional properties defined on the megathrust. Secondly, in order to properly resolve seismic events within the wedge, the resolution is increased, with the minimum cell size decreased to $50 \mathrm{~m}$.

We emphasize that we do not predefine any splay-faults in the models - they spontaneously arise at their characteristic orientation (e.g. Preuss et al. 2019). Our results indicate that, in the early stages of the simulations, for example for the first three events, seismic ruptures remain confined on the megathrust (Fig. 7a). This occurs because the stress distribution within the wedge is largely homogeneous. When stress evolves in response to previous seismic events, dynamic fault branching occurs within the wedge and seismic events propagate through splay-faults (Fig. 7b). Our models show the spontaneous occurrence of both landward-dipping and seaward-dipping splay-faults (Figs $7 \mathrm{~b}$ and c). Seismic events normally propagate from the lower edge of the locked portion of the megathrust towards the shallow region and, occasionally, they activate a splay-fault in the shallower region. This process leads to the propagation of either a single forethrust or two splay-faults (forethrust and backthrust), which result in Y-shaped structure (Fig. 7c). Our simulations display an early stage of shear localization, in which the splay-faults grow aseismically from the intersection with the megathrust (Fig. 7d). Since the initial set of frictional parameters results in a critical nucleation size larger than or close to the length of splay-faults, dynamic events are not capable to nucleate within the wedge. However, when an event nucleates along the downdip edge of the megathrust, coseismic slip propagates updip activating a growing splay-fault, which transitions to faster slip (Fig. 7e). Overall, both forethrust and backthrust exhibit similar behaviour. The triggering process is controlled by the stress state within the wedge and the updip propagation of slip from the megathrust. As expected, the locus of maximum uplift depends on the location of the active splay-fault. In particular, the occurrence of splay-fault events shrinks the wavelength of coseismic surface deformation by localizing a high-amplitude signal.

During the interseismic periods, active deformation occurs mostly at the locked-creeping transition. This effect is controlled by the velocity-weakening to VS transition. Based on the critical taper theory, this result is consistent with the notion that the forearc region-above the seismogenic portions of the megathrust - is mechanically stable, while the downdip VS portion of the megathrust is maintained in a critical state as a result of the stress transfer operated by coseismic and post-seismic deformation (Wang \& Hu 2006; Cubas et al. 2013). As shown in previous studies (e.g. Ruh et al. 2012; Dal Zilio et al. 2020c), the evolution of the wedge follows closely the prediction of the critical taper theory (Dahlen 1984), with localized deformation on discrete faults and shear bands. In particular, the onset, development, and arrest 

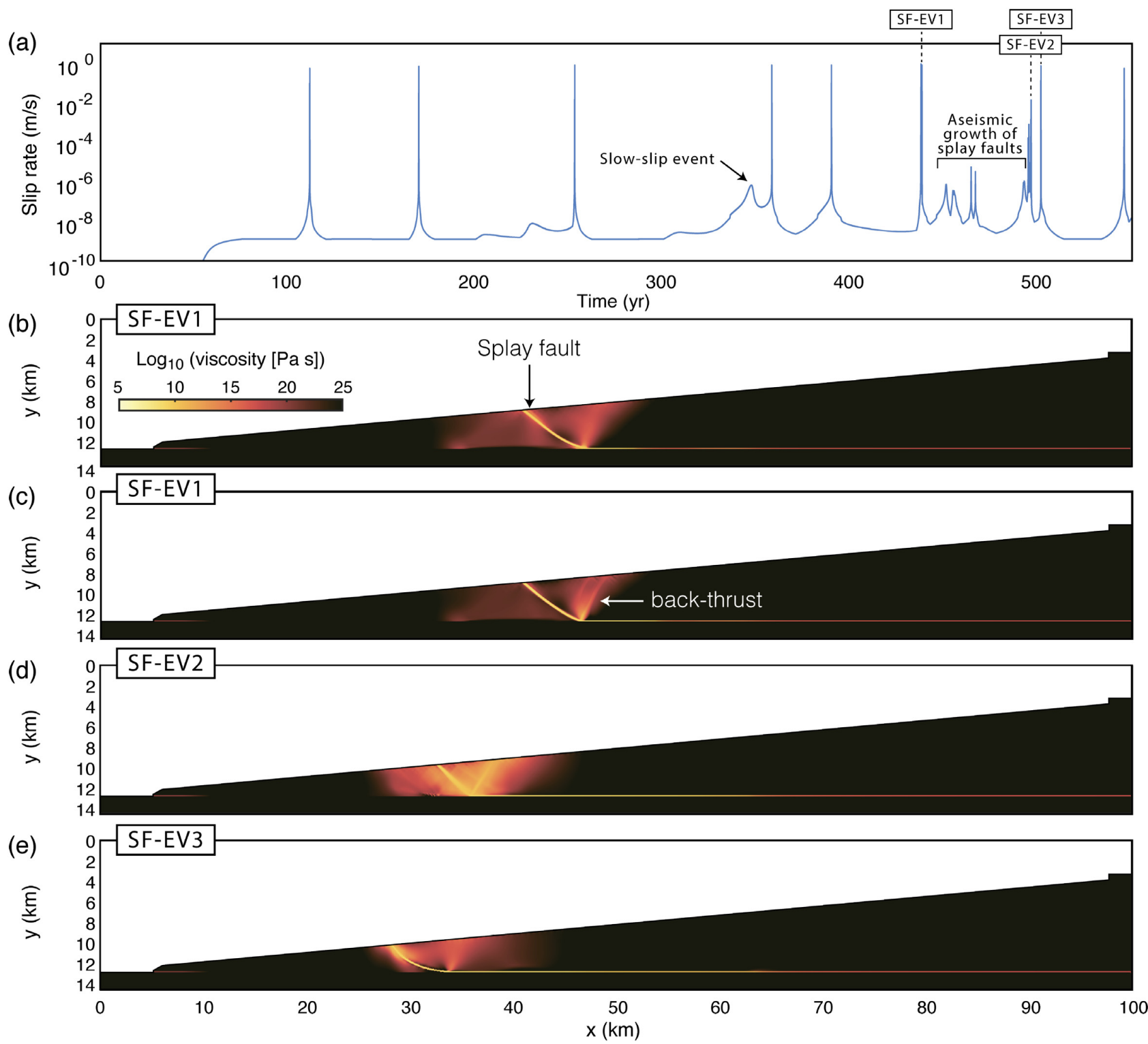

Figure 7. Overview of the results for the simulation with splay-fault events. (a) Temporal evolution of maximum slip velocity. After a sequence of megathrust events, three splay-fault events occur within the wedge (SF-EV1-3). (b-e) Representative snapshots of the viscosity distribution displaying the propagation of the three splay-fault events within the wedge. Seismic events typically nucleate at the locked-creeping transition zone $(x \sim 50-60 \mathrm{~km})$ and propagate updip towards the trench, occasionally activating splay-faults in the shallower region (SF-EV1). (c) The activation of a seaward-dipping splay-fault is sometimes accompanied by a landward-dipping backthrust. During the interseismic periods, strain localization within the wedge can cause the slow (aseismic) growth of splay-faults (SF-EV2), which precede the propagation of fast, seismic events (SF-EV3).

of splay-faults due to the onset of another splay-fault event is in good agreement with the prediction of thrusting sequences deduced from the limit analysis (Cubas et al. 2008). However, our simulations display an increase of the splay fault dip angle, which occurs at the transition between the seismic and aseismic faulting stage. This effect is controlled by the slip rate: seismic fault growth causes a substantial increase in dynamic stresses, stress orientations and friction coefficient at and ahead of the propagating fault tip (e.g. Preuss et al. 2019). As a result, splay-faults grow aseismically with a low angle in the early stages, and then they propagate with a steeper angle during the coseismic phase. These results suggest that seismically formed faults can be distinguished from aseismically formed faults, which are in good agreement with the structural profiles from different accretionary wedges worldwide (Hubbard et al. 2015; Pfiffner 2017). 

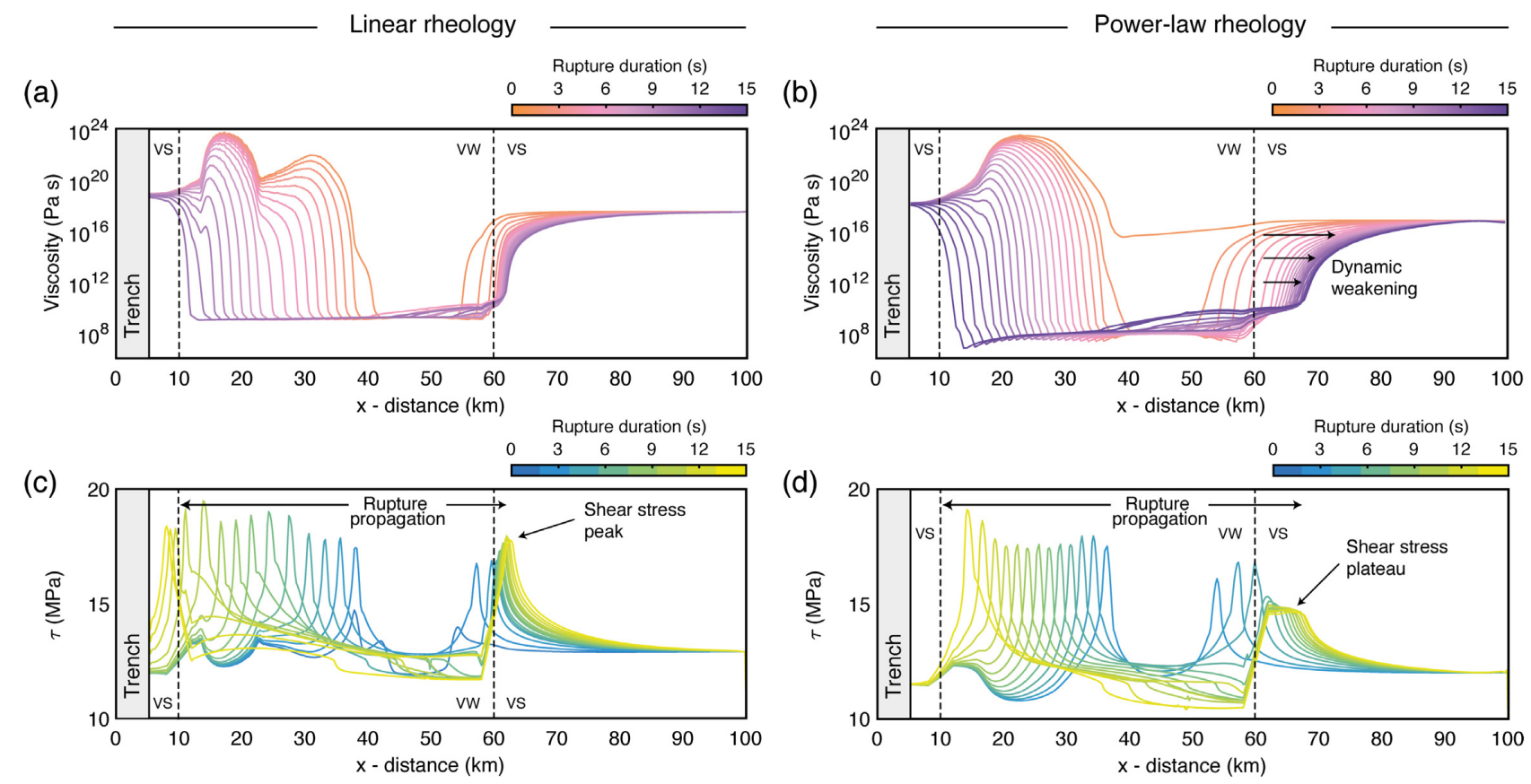

Figure 8. Spatiotemporal evolution of (a, c) viscosity and (c, d) shear stress on the megathrust during dynamic rupture in models with linear viscosity and power-law rheology, respectively. Colourbars indicate the temporal profile on the megathrust from the beginning of the dynamic rupture. A drop in viscosity causes coseismic weakening in the transition region and deeper penetration of dynamic rupture, smoothing the rupture arrest and the associated stress concentration.

\section{DISCUSSION}

\subsection{Dynamic weakening of temperature-dependent power-law rheology}

Subduction megathrusts accommodate slow motion between tectonic plates through a spectrum of slip modes ranging from stable creep to slow-slip events and large earthquakes. This spectrum of slip modes is often assumed to be spatially separated within different segments of subduction megathrusts: a shallower, velocity-weakening frictional segment that leads to unstable slip transients, and a deeper VS frictional segment characterized by stable sliding (Fig. 1).

Our models incorporating the effect of temperature-dependent rheology demonstrate that coseismic weakening due to rapid drop in viscosity allows unstable slip to propagate even in segments that can creep between events (Fig. 8). When a dynamic rupture occurs, strain rate localizes on the megathrust and viscosity decreases several orders of magnitude (Figs $8 \mathrm{a}$ and b). Notably, when our fault model incorporates temperature-dependent rheology (Section 3.2), viscosity reaches a lower coseismic value than the models with linear viscosity ( $c f$. Figs 8 a and $b$ ). This process results in an enhanced dynamic weakening mechanism at the locked-creeping transition, which allows dynamic ruptures to propagate deeper even with lower shear stress than required for rupture propagation ( $c f$. Figs $8 \mathrm{c}$ and d). Dynamic ruptures manage to enter the VS fault zone due to stress concentration at the rupture front. Whether the rupture can continue depends on the activation of coseismic weakening of viscosity.

As a result, although coseismic slip is largely confined within the seismogenic zone, the region at and below the locked-creeping transition can also participate in the event, thus increasing the final length, slip, and magnitude ( $c f$. Figs $9 \mathrm{a}$ and b). Such emerging behaviour provides new physical insights into the conceptual notion of a conditionally stable fault (Scholz 1998). Throughout the interseismic periods, and even before a seismic event, the region at and below the locked-creeping transition can be creeping (that is, appear to being fully decoupled), and yet can also experience seismic slip, in contrast to the notion that large earthquakes rupture mostly locked patches or asperities (e.g. Lay et al. 1982; Perfettini et al. 2010). In our models, the enhanced dynamic weakening observed in temperature-dependent rheology models impacts the entire rupture length, including the shallower portion of the fault.

The resulting enhanced dynamic weakening process observed in our models provides a possible explanation for the occurrence of large slip during M8.5+ earthquakes. For example, the 2011 M9.1 Tohoku-Oki earthquake resulted in a exceptionally large seismic slip, even in the areas that had been assumed to be creeping (e.g. Loveless \& Meade 2010; Simons et al. 2011; Ide et al. 2011). In light of our modelling, the locked-creeping transition on large subduction megathrusts may not correspond to the bottom of the seismogenic zone inverted from surface geodetic observations (Avouac 2015), which is often used to infer the actual depth distribution of slip rates from a simplified dislocation model (Savage 1983). Previous studies have demonstrated that interseismically creeping patches can occasionally participate in large seismic events due to dynamic weakening (Noda \& Lapusta 2013). Furthermore, Jiang \& Lapusta (2016) have demonstrated that deeper penetration of dynamic ruptures may be quite common for large events. By analyzing this phenomenon in a friction-based fault model, they provide an explanation on the apparent interseismic quiescence of faults experiencing large earthquakes. Our models demonstrate that enhanced dynamic 
(a)

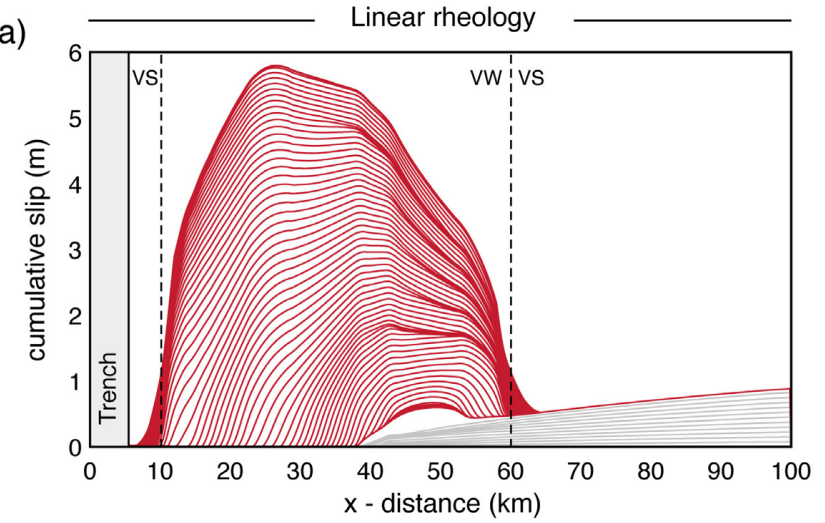

(b)

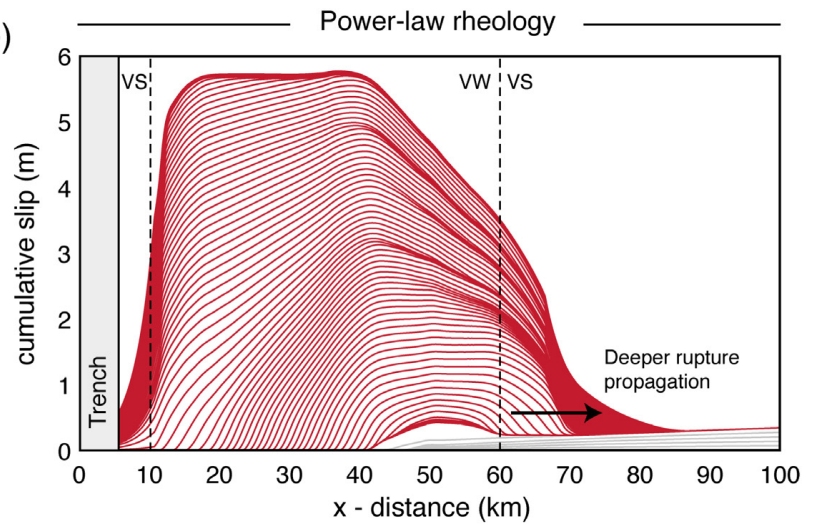

Figure 9. Cumulative slip on the megathrust for one representative complete rupture from the simulations accounting for (a) linear rheology and (b) temperaturedependent power-law rheology. Red lines indicate the coseismic slip every $1 \mathrm{~s}$ when the maximum slip velocity exceeds the threshold of $0.0667 \mathrm{~m} \mathrm{~s}^{-1}$ (see eq. 35), while grey lines (every $10 \mathrm{yr}$ ) illustrate the interseismic (aseismic) behaviour of the fault.

weakening and deeper penetration of large earthquakes can hold even for viscoplastic deeper fault extensions, which dynamically localize and weaken the fault due to non-linear strain-rate effects. While our models mimic megathrust subduction zones, the results have relevance for the seismic hazard of strike-slip faults, which would be increased by the extended downdip rupture limit of subvertical faults.

\subsection{Post-seismic deformation: after-slip versus viscous flow}

Slip response in the presented models allows us to examine the deformation through the post-seismic periods. Furthermore, solutions of fault slip in space and time can be directly compared against analytical solutions to demonstrate the accuracy of our modelling approach. Since our models account for both frictional afterslip and bulk viscous flow, such comparison can help determine their relative contributions to post-seismic deformation in the VS fault zone.

Fig. 10 shows the spatiotemporal evolution of slip velocity during a representative dynamic event for the reference model with temperature-dependent power-law rheology. This event nucleates and propagates both updip and downdip, passing through the entire VW fault zone and arresting in the shallow and deep VS regions. The relatively large $\bar{\sigma}$ results in a large VS effect $\bar{\sigma}(a-b)$, leading the dynamic rupture to arrest shortly upon penetrating the VS regions (Fig. 10a). As expected from the rate-and-state frictional fault, the VS region has interseismic slip velocities that are close to the plate rate $\left(V_{p}\right)$ of $2 \times 10^{-9} \mathrm{~m} \mathrm{~s}^{-1}$. However, shortly after the dynamic rupture, slip velocity increases due to post-seismic deformation (Fig. 10a).

Evolution of post-seismic deformation for two representative points P1 and P2 are shown in Fig. 10. Point P1 is located near the locked-creeping transition at $x=65 \mathrm{~km}$, that is where the temperature is $\sim 390{ }^{\circ} \mathrm{C}$, whereas point $\mathrm{P} 2$ is located deeper $(x=75 \mathrm{~km})$ at a temperature of $\sim 450^{\circ} \mathrm{C}$. Histories of slip velocity (Fig. 10b) and cumulative slip (Fig. 10c) show that, shortly after the dynamic rupture, slip velocity increases due to post-seismic deformation, accumulating several centimeters of slip. This phenomenon occurs because seismic slip causes a positive static stress change in the VS fault zone, which leads to an increase in aseismic slip rates that decay monotonically towards $V_{p}$ (Fig. 10b). Since point P1 is located closer to the rupture arrest, it experiences a larger static stress change and a higher slip velocity variation than point P2. Notably, the post-seismic deformation of point P1 follows the analytical solution given by Perfettini \& Avouac (2004), which is derived in a 1-D spring block with VS friction in response from a steady state sliding to a velocity step in response to a change in shear stress:

$$
V(t)=\frac{V^{+} e^{t / t_{r}}}{1+\frac{V^{+}}{V_{p}}\left(e^{t / t_{r}}-1\right)} ;
$$

where

$t_{r}=\frac{(a-b) p}{\zeta V_{p}} ;$

$\zeta=\frac{2}{\pi} \frac{\mu^{*}}{L_{v s}}$,

where $t_{r}$ is the decay time from the initial maximum value of slip velocity $V^{+}$(immediately after the earthquake) and $L_{\mathrm{vs}}=40 \mathrm{~km}$ is the length of the VS fault zone. This agreement between the analytical solution and our models indicate that, close to the locked-creeping transition zone, the post-seismic deformation is mainly controlled by afterslip. On the other hand, point P2 displays a post-seismic evolution that agrees well with the shear zone model of post-seismic creep proposed by Montési (2004):

$V(t)=V^{+}\left(1+\left(1-\frac{1}{n}\right) t\right)^{-1 /\left(1-\frac{1}{n}\right)}$. 
(a)

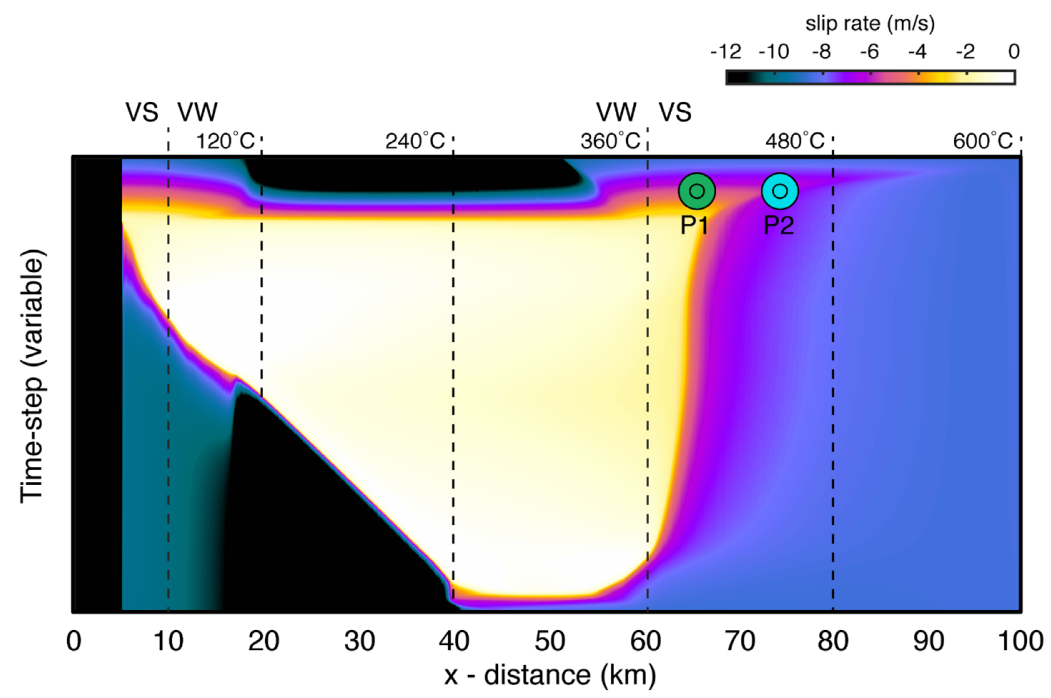

(b)

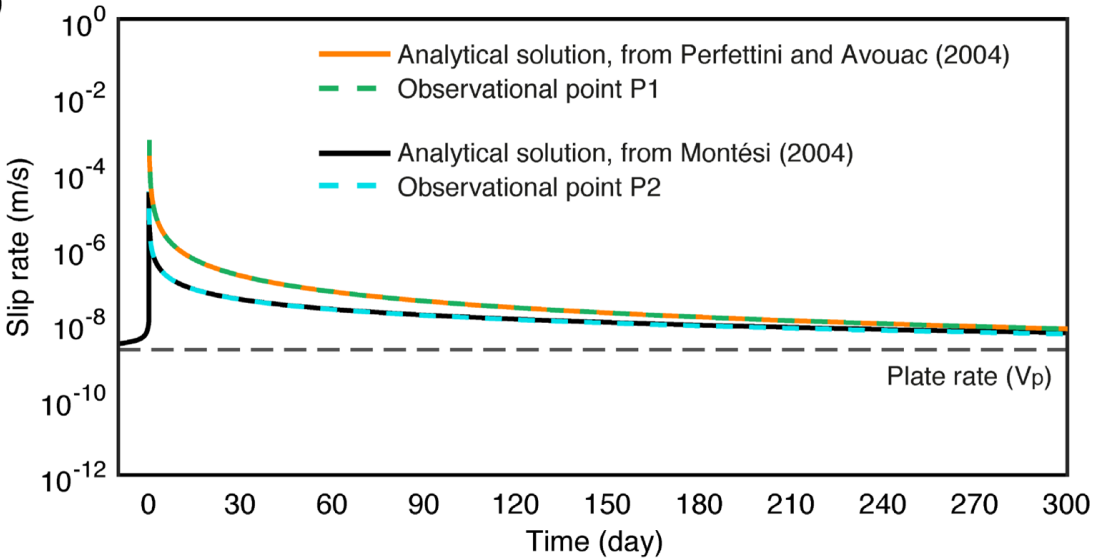

(c)

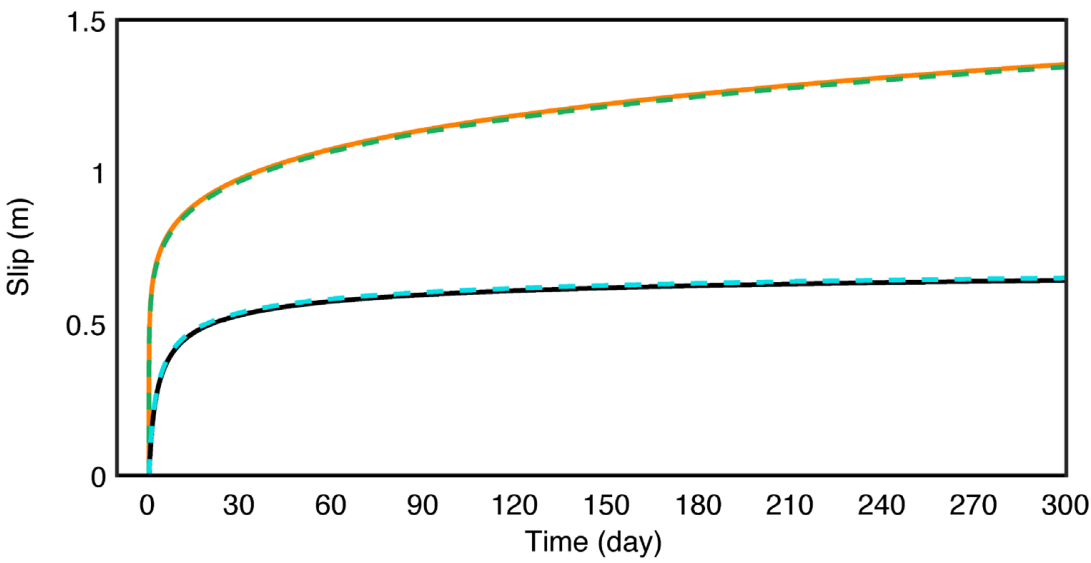

Figure 10. Dynamic rupture, post-seismic relaxation, and interseismic healing. (a) Spatiotemporal evolution of slip rate during the fifth earthquake in the simulation shown in Fig. 6a. Time zero is defined immediately before the beginning of the event. Note that, in order to visualize the evolution of the dynamic rupture and post-seismic relaxation, the vertical axis displays the time step. Temporal evolution of (b) slip velocity and (c) cumulative from from the observational points P1 and P2 in the velocity-strengthening fault zone, and comparison with analytical approximation for post-seismic relaxation given by Perfettini \& Avouac (2004) and Montési (2004). Note that the beginning of the post-seismic deformation it is defined by the maximum slip rate $\left(V^{+}\right)$on points P1 and P2 immediately after the earthquake.

This general relaxation law indicates that the displacement history of the viscous shear zone is controlled by the inverse stress exponent $1 / n$ of the fault rheology involved in post-seismic viscous creep. This means that the stress exponent modulates the curvature of this function, and suggest that post-seismic creep ceases earlier for viscous behaviour. At the same time, this general relaxation law shows that stress-driven afterslip on a VS fault zone is functionally similar to the case of a power-law rheology relating strain rate to stress with a high power-law exponent $n$. 
Various mechanisms for post-seismic creep have been proposed, for example poroelastic rebound (e.g. Peltzer et al. 1998), afterslip on the earthquake rupture area (e.g. Marone et al. 1991), dilatant effect at the downdip end of seismogenic zone (Liu 2013) and viscous creep in a localized shear zone (e.g. Savage et al. 1994; Freed \& Bürgmann 2004). However, determining the relative contributions of different post-seismic creep mechanisms remains challenging. Our modelling approach, together with post-seismic data from natural earthquakes over a broad range of time scales, can, in principle, be used to discriminate the relative contributions of afterslip and viscous flow. However, this would be a non-trivial task, mainly due to general assumptions, broad range of potential model parameters, errors in the model structure and observed variables and covariation of parameters.

\subsection{Future avenues for research}

Future studies can make use of this methodology to investigate a number of different phenomena. The proposed setup is rather simple, but it can be applied to investigate how subduction zone earthquake sequences affect normal and reverse faulting in the fore-arc (Loveless et al. 2010), and whether the seismic behaviour is intrinsically related to the long-term tectonic features and segmentation of the accretionary wedge, as suggested by analogue models (Rosenau \& Oncken 2009). The developed methodology also presents a promising avenue for investigating how the subduction interface roughness affects the occurrence of large earthquakes (e.g. van Rijsingen $e t a l$. 2018), and how the size, rheology and spacing of asperities influence the seismic pattern occurring within the seismogenic megathrust (Corbi et al. 2017). Future work will also focus on more realistic scenarios of different subduction zones, collisional orogens, extensional settings and strike-slip faults. In particular, one can investigate how multiple earthquake cycles affect the building of topography, surface denudation, structural segmentation, post-seismic relaxation and isostatic compensation (Dal Zilio et al. 2021).

Over the last decades, seismic and geodetic observations have revealed complex interactions of earthquakes, slow-slip transients and stable creep. Investigating under which conditions slow-slip events are mostly controlled by viscoplastic bulk properties (e.g. Lambert \& Barbot 2016; Gao \& Wang 2017; Viesca \& Dublanchet 2018; Goswami \& Barbot 2018; Fagereng \& Beall 2021), rather than fault properties, represents an important topic in earthquake physics. Also, our numerical experiments reveal that non-linear viscous deformation at coseismic slip rates may be responsible for an enhanced dynamic weakening mechanism along megathrust faults. The similarity of the weakening process involved during coseismic slip is in good agreement with high-speed laboratory experiments of viscous weakening documented across a wide range of fault materials (Pozzi et al. 2021). Investigating these highly effective fault lubrication processes would improve our understanding of rupture propagation and radiation, and why some fault segments can become destructive as a result of dynamic weakening (e.g. Noda \& Lapusta 2013).

Future developments can also incorporate different assumptions about the nature of the megathrust fault. In the presented models, the width of the fault zone is assumed to be $20 \mathrm{~m}$, which may be too large, especially for the seismogenic zone (e.g. Rice 2006, and references therein). However, exhumed fault zones make it clear that faults are not 2-D features at the junction of two distinct bodies of rock, but instead evolve into complex damage zones (e.g. Mitchell \& Faulkner 2009). To address this non-trivial task, new studies have contributed to improve our theoretical understanding of earthquakes and other seismic phenomena as volumetric, bulk-rock processes (Pranger et al. 2021; Lyakhovsky et al. 2011; Thakur \& Huang 2021; Gabriel et al. 2021; Behr et al. 2021).

An important ingredient to add to the modelling in the future is the poroelastic effect of fluid pressure variations, which can be used to investigate how crustal stresses and fluid pressures within the oceanic crust evolve before and during fast- and slow-slip events (e.g. Warren-Smith et al. 2019; Heimisson et al. 2019; Zhu et al. 2020). Further developments can also incorporate shear heating, thermal runaway, and grain size evolution (e.g. Ricard \& Bercovici 2009), needed to analyse the onset of highly localized viscous creep in pre-existing, fine-grained shear zones, with possible implications for intermediate-depth earthquakes (e.g. Kelemen \& Hirth 2007; Thielmann et al. 2015). Finally, in order to make a full comparison to megathrust earthquakes in different geological settings, we need to understand how the reported viscoelastic instabilities manifest in three dimensions.

\section{CONCLUSIONS}

We have developed, on the basis of prior studies, a 2-D methodology for simulating sequences of seismic and aseismic slip on a visco-elastoplastic subduction megathrust subjected to slow tectonic loading. Our approach resolves all stages of earthquake cycle due to long-term tectonic loading, including steady fault slip, viscous flow, nucleation and propagation of dynamic ruptures, post-seismic deformation and aseismic transients. Building on previous code based on visco-elasto-plastic rheologies (Gerya \& Yuen 2007), we include the following capabilities:

(i)An invariant and regularized version of rate- and state-dependent friction formulation (Herrendörfer et al. 2018), and an adaptive timestepping to resolve all stages of earthquake cycle (Lapusta et al. 2000).

(ii)Both FD formulation of inertial effects and QD approximation through the implementation of the radiation damping approximation (Rice 1993).

(iii)Both linear viscous rheologies and power-law rheologies (Appendix A), which are solved using a rapidly converging Newton-Raphson scheme to obtain an effective viscosity (Appendix B). 
(iv)An adaptive viscosity for the free surface approximation to modulate the effective viscosity throughout the earthquake cycle, which allows to maintain low stress levels at the free surface during the propagation of fast slip events.

(v)Off-fault plasticity and spontaneous development of splay-faults in the bulk.

We have investigated spontaneously occurring slip instabilities that nucleate and propagate on a subduction megathrust due to thermomechanical coupling of rate-and-state friction and non-linear viscoelastic rheologies. Slip response in the presented models, which have a relatively simple fault geometry and distributions of friction properties, involves seismic and aseismic transients, which the latter arising in the areas of velocity-weakening regions close to locked-creeping transition zone. Such episodes of spontaneous aseismic fault slip tend to occur in the late stages of interseismic periods, and constitute propagating nucleation attempts. Their occurrence depends on the critical nucleation size. In our numerical experiments, we choose frictional parameters that make the critical nucleation size a significant fraction of the fault width (i.e. $\sim 1 / 6$ the length of the seismogenic zone) to make the problem numerically resolvable. Large nucleation sizes may also be possible for certain fault conditions, for example due to highly elevated pore pressure (Liu \& Rice 2007), dilatancy effects (Segall et al. 2010) and/or when velocity-weakening slip patches are smaller or close to the critical dimension needed for earthquake nucleation (e.g. Veedu \& Barbot 2016; Dal Zilio et al. 2020b).

Our results suggest that non-linear power-law rheology can provide an enhanced dynamic weakening due to a viscosity drop at high slip rates. Such mechanism would lead to a larger cumulative slip and stress drop, allowing dynamic ruptures to penetrate deeper into the locked-creeping transition and, partially, into the VS fault zone.

The developed methodology can be used to study many aspects of fault slip, such as earthquake nucleation and propagation in heterogeneous faults, temperature-dependent viscoelastic processes, post-seismic deformation due to a combination of mechanisms and slip response of faults with complex geometry and rheology. Recent improvements in availability and quality of seismic and geodetic data have revealed complex interactions of seismic and aseismic slip. Interpreting this rich information through forward modelling developed in this study can help us determine the constitutive behaviour and properties of natural faults.

\section{CODE AVAILABILITY}

Computer code used within the manuscript is still under development and is available from the corresponding author upon reasonable request.

\section{ACKNOWLEDGEMENTS}

We thank Casper Pranger, Robert Herrendörfer, Camilla Penney, Sylvain Barbot, Valére Lambert and Whitney Behr for discussions. This research was supported by the Swiss National Science Foundation (SNSF) (grants No. P2EZP2_184307 and P400P2_199295), the United States Geological Survey (USGS) Earthquake Hazard Program (grant No. GP21AP10037) and by the Cecil \& Sally Drinkward postdoctoral fellowship of the Department of Mechanical and Civil Engineering at the California Institute of Technology. Numerical simulations were performed on ETH cluster Euler. We thank the Editor Margarita Segou, Duo Li and an anonymous reviewers for providing insightful comments that helped to improve the quality of this paper.

\section{DATA AVAILABILITY}

The data underlying this paper will be shared on reasonable request to the corresponding author.

\section{REFERENCES}

Allison, K.L. \& Dunham, E.M., 2018. Earthquake cycle simulations with rate-and-state friction and power-law viscoelasticity, Tectonophysics, 733, 232-256.

Avouac, J.-P., 2015. From geodetic imaging of seismic and aseismic fault slip to dynamic modeling of the seismic cycle, Ann. Rev. Earth planet. Sci., 43, 233-271.

Barbot, S., 2018. Asthenosphere flow modulated by megathrust earthquake cycles, Geophys. Res. Lett., 45(12), 6018-6031.

Beeler, N., Tullis, T., Blanpied, M. \& Weeks, J., 1996. Frictional behavior of large displacement experimental faults, J. geophys. Res., 101(B4), 8697-8715.

Behr, W.M., Gerya, T.V., Cannizzaro, C. \& Blass, R., 2021. Transient slow slip characteristics of frictional-viscous subduction megathrust shear zones, $A G U A d v$., 2(3),

Ben-Zion, Y. \& Rice, J.R., 1995. Slip patterns and earthquake populations along different classes of faults in elastic solids, J. geophys. Res., 100(B7), 12959-12983.

Beroza, G.C. \& Ide, S., 2011. Slow earthquakes and nonvolcanic tremor, Ann. Rev. Earth planet. Sci., 39, 271-296.
Bhattacharya, P., Rubin, A.M. \& Beeler, N.M., 2017. Does fault strengthening in laboratory rock friction experiments really depend primarily upon time and not slip?, J. geophys. Res., 122(8), 6389-6430.

Bilek, S.L. \& Lay, T., 2018. Subduction zone megathrust earthquakes, Geosphere, 14(4), 1468-1500.

Blanpied, M., Lockner, D. \& Byerlee, J., 1991. Fault stability inferred from granite sliding experiments at hydrothermal conditions, Geophys. Res. Lett., 18(4), 609-612.

Blum, L., 2019. Numerical implementation of non-linear viscous rheology for meteorite impact simulations, Master's thesis, ETH Zurich.

Bruhat, L. \& Segall, P., 2017. Deformation rates in northern Cascadia consistent with slow updip propagation of deep interseismic creep, J. geophys. Int., 211(1), 427-449.

Bürgmann, R., 2018. The geophysics, geology and mechanics of slow fault slip, Earth planet. Sci. Lett., 495, 112-134.

Cochard, A. \& Madariaga, R., 1996. Complexity of seismicity due to highly rate-dependent friction, J. geophys. Res., 101(B11), 25 321-25 336.

Corbi, F., Funiciello, F., Brizzi, S., Lallemand, S. \& Rosenau, M., 2017. Control of asperities size and spacing on seismic behavior of subduction megathrusts, Geophys. Res. Lett., 44(16), 8227-8235. 
Crameri, F. et al., 2012. A comparison of numerical surface topography calculations in geodynamic modelling: an evaluation of the "sticky air'method, J. geophys. Int., 189(1), 38-54.

Crupi, P. \& Bizzarri, A., 2013. The role of radiation damping in the modeling of repeated earthquake events, Ann. Geophys., 56(1), doi:10.4401/ag6200.

Cubas, N., Leroy, Y. \& Maillot, B., 2008. Prediction of thrusting sequences in accretionary wedges, J. geophys. Res., 113(B12), doi:10.1029/2008JB005717.

Cubas, N., Avouac, J.-P., Souloumiac, P. \& Leroy, Y., 2013. Megathrust friction determined from mechanical analysis of the forearc in the Maule earthquake area, Earth planet. Sci. Lett., 381, 92-103.

D’Acquisto, M., Dal Zilio, L., Molinari, I., Kissling, E., Gerya, T. \& van Dinther, Y., 2020. Tectonics and seismicity in the northern Apennines driven by slab retreat and lithospheric delamination, Tectonophysics, $\mathbf{7 8 9}$,

Dahlen, F., 1984. Noncohesive critical coulomb wedges: an exact solution, J. geophys. Res., 89(B12), $10125-10133$.

Dal Zilio, L., Kissling, E., Gerya, T. \& van Dinther, Y., 2020a. Slab rollback orogeny model: a test of concept, Geophys. Res. Lett., 47(18),.

Dal Zilio, L., Lapusta, N. \& Avouac, J.-P., 2020b. Unraveling scaling properties of slow-slip events, Geophys. Res. Lett., 47(10),.

Dal Zilio, L., Ruh, J. \& Avouac, J.-P., 2020c. Structural evolution of orogenic wedges: interplay between erosion and weak décollements, Tectonics, 39(10),

Dal Zilio, L., Hetényi, G., Hubbard, J. \& Bollinger, L., 2021. Building the Himalaya from tectonic to earthquake scales, Nat. Rev. Earth Environ., 2, 251-268.

Day, S.M., Dalguer, L.A., Lapusta, N. \& Liu, Y., 2005. Comparison of finite difference and boundary integral solutions to three-dimensional spontaneous rupture, J. geophys. Res., 110(B12), doi:10.1029/2005JB003813.

De Borst, R. \& Sluys, L., 1991. Localisation in a Cosserat continuum under static and dynamic loading conditions, Comput. Methods Appl. Mech. Eng., 90(1-3), 805-827.

Dieterich, J., 2007. Applications of rate-and state-dependent friction to models of fault-slip and earthquake occurrence, in Treatise on Geophysics, pp. 107-121, Elsevier.

Dieterich, J.H., 1979. Modeling of rock friction: 1. Experimental results and constitutive equations, J. geophys. Res., 84(B5), 2161-2168.

Dieterich, J.H. et al. , 1981. Constitutive properties of faults with simulated gouge, in Mechanical Behavior of Crustal Rocks, pp. 103-120, eds Carter, N.L., Friedman, M., Logan, J.M. \& Stearns, D.W., Geophysical Monograph Series, American Geophysical Union.

Dunham, E.M., Favreau, P. \& Carlson, J., 2003. A supershear transition mechanism for cracks, Science, 299(5612), 1557-1559.

Erickson, B.A. \& Dunham, E.M., 2014. An efficient numerical method for earthquake cycles in heterogeneous media: alternating subbasin and surface-rupturing events on faults crossing a sedimentary basin, J. geophys. Res., 119(4), 3290-3316.

Erickson, B.A., Dunham, E.M. \& Khosravifar, A., 2017. A finite difference method for off-fault plasticity throughout the earthquake cycle, J. Mech. Phys. Solids, 109, 50-77.

Erickson, B.A. et al., 2020. The community code verification exercise for simulating sequences of earthquakes and aseismic slip (seas), Seismol. Res. Lett., 91(2A), 874-890.

Fagereng, Å. \& Beall, A., 2021. Is complex fault zone behaviour a reflection of rheological heterogeneity?, Phil. Trans. R. Soc. A, 379(2193),

Freed, A.M. \& Bürgmann, R., 2004. Evidence of power-law flow in the Mojave desert mantle, Nature, 430(6999), 548-551.

Gabriel, A.-A., Li, D., Chiocchetti, S., Tavelli, M., Peshkov, I., Romenski, E. \& Dumbser, M., 2021. A unified first-order hyperbolic model for nonlinear dynamic rupture processes in diffuse fracture zones, Phil. Trans. $R$. Soc. A, 379(2196),

Gao, X. \& Wang, K., 2017. Rheological separation of the megathrust seismogenic zone and episodic tremor and slip, Nature, 543(7645), 416.

Gerya, T., 2019. Introduction to Numerical Geodynamic Modelling, Cambridge Univ. Press.
Gerya, T. \& Yuen, D., 2007. Robust characteristics method for modelling multiphase visco-elasto-plastic thermo-mechanical problems, Phys. Earth planet. Inter., 163(1), 83-105.

Goswami, A. \& Barbot, S., 2018. Slow-slip events in semi-brittle serpentinite fault zones, Sci. Rep., 8(1), 6181,.

Heimisson, E.R., Dunham, E.M. \& Almquist, M., 2019. Poroelastic effects destabilize mildly rate-strengthening friction to generate stable slow slip pulses, J. Mech. Phys. Solids, 130, 262-279.

Herrendörfer, R., 2018. Modeling of the slip spectrum along mature and spontaneously forming faults in a visco-elasto-plastic continuum, $P h D$ thesis, ETH Zurich.

Herrendörfer, R., Gerya, T. \& Dinther, Y., 2018. An invariant rate- and state-dependent friction formulation for viscoeastoplastic earthquake cycle simulations, J. geophys. Res., 123(6), 5018-5051.

Heuret, A., Conrad, C., Funiciello, F., Lallemand, S. \& Sandri, L., 2012. Relation between subduction megathrust earthquakes, trench sediment thickness and upper plate strain, Geophys. Res. Lett., 39(5),

Houston, H., Delbridge, B.G., Wech, A.G. \& Creager, K.C., 2011. Rapid tremor reversals in Cascadia generated by a weakened plate interface, Nat. Geosci., 4(6), 404-409.

Huang, Y., Meng, L. \& Ampuero, J.-P., 2012. A dynamic model of the frequency-dependent rupture process of the 2011 Tohoku-Oki earthquake, Earth, Planets Space, 64(12), 1061-1066.

Hubbard, J., Barbot, S., Hill, E.M. \& Tapponnier, P., 2015. Coseismic slip on shallow décollement megathrusts: implications for seismic and tsunami hazard, Earth-Sci. Rev., 141, 45-55.

Hyndman, R.D. \& Wang, K., 1993. Thermal constraints on the zone of major thrust earthquake failure: the Cascadia subduction zone, J. geophys. Res., 98(B2), 2039-2060.

Ide, S., Baltay, A. \& Beroza, G.C., 2011. Shallow dynamic overshoot and energetic deep rupture in the $2011 \mathrm{Mw} 9.0$ Tohoku-Oki earthquake, Science, 332(6036), 1426-1429.

Jiang, J. \& Lapusta, N., 2016. Deeper penetration of large earthquakes on seismically quiescent faults, Science, 352(6291), 1293-1297.

Jiang, J. et al., 2021. Community-driven code comparisons for threedimensional dynamic modeling of sequences of earthquakes and aseismic slip (seas), Earth Space Sci. Open Arch., 55.

Jolivet, R. \& Frank, W., 2020. The transient and intermittent nature of slow slip, $A G U A d v$., 1(1),

Kaneko, Y., Avouac, J.-P. \& Lapusta, N., 2010. Towards inferring earthquake patterns from geodetic observations of interseismic coupling, Nat. Geosci., 3(5), 363-369.

Kaneko, Y., Ampuero, J.-P. \& Lapusta, N., 2011. Spectral-element simulations of long-term fault slip: effect of low-rigidity layers on earthquakecycle dynamics, J. geophys. Res., 116(B10), doi:10.1029/2011JB008395.

Kato, A. \& Ben-Zion, Y., 2020. The generation of large earthquakes, Nat. Rev. Earth Environ., 2, 26-39.

Kato, N., 2002. Seismic cycle on a strike-slip fault with rate-and statedependent strength in an elastic layer overlying a viscoelastic half-space, Earth, Planets Space, 54(11), 1077-1083.

Kawamura, H., Hatano, T., Kato, N., Biswas, S. \& Chakrabarti, B.K., 2012. Statistical physics of fracture, friction, and earthquakes, Rev. Modern Phys., 84(2), 839-884.

Kelemen, P.B. \& Hirth, G., 2007. A periodic shear-heating mechanism for intermediate-depth earthquakes in the mantle, Nature, 446(7137), 787790

Lambert, V. \& Barbot, S., 2016. Contribution of viscoelastic flow in earthquake cycles within the lithosphere-asthenosphere system, Geophys. Res. Lett., 43(19), 10-142.

Lapusta, N. \& Liu, Y., 2009. Three-dimensional boundary integral modeling of spontaneous earthquake sequences and aseismic slip, J. geophys. Res., 114(B9), doi:10.1029/2008JB005934.

Lapusta, N., Rice, J.R., Ben-Zion, Y. \& Zheng, G., 2000. Elastodynamic analysis for slow tectonic loading with spontaneous rupture episodes on faults with rate-and state-dependent friction, J. geophys. Res., 105(B10), $23765-23789$. 
Lavier, L.L., Tong, X. \& Biemiller, J., 2021. The mechanics of creep, slow slip events and earthquakes in mixed brittle-ductile fault zones, J. geophys. Res., 126(2), doi:10.1029/2020JB020325.

Lay, T., 2015. The surge of great earthquakes from 2004 to 2014, Earth planet. Sci. Lett., 409, 133-146.

Lay, T., Kanamori, H. \& Ruff, L., 1982. The asperity model and the nature of large subduction zone earthquakes, Predicition Res., 1, 3-71.

Lay, T., Kanamori, H., Ammon, C.J., Koper, K.D., Hutko, A.R., Ye, L., Yue, H. \& Rushing, T.M., 2012. Depth-varying rupture properties of subduction zone megathrust faults, J. geophys. Res., 117(B4), doi:10.1029/2011JB009133.

Liu, Y., 2013. Numerical simulations on megathrust rupture stabilized under strong dilatancy strengthening in slow slip region, Geophys. Res. Lett., 40(7), 1311-1316.

Liu, Y. \& Rice, J.R., 2007. Spontaneous and triggered aseismic deformation transients in a subduction fault model, J. geophys. Res., 112(B9), doi:10.1029/2007JB004930.

Loveless, J.P. \& Meade, B.J., 2010. Geodetic imaging of plate motions, slip rates, and partitioning of deformation in Japan, J. geophys. Res., 115(B2), doi: 10.1029/2008JB006248.

Loveless, J.P., Allmendinger, R.W., Pritchard, M.E. \& González, G., 2010. Normal and reverse faulting driven by the subduction zone earthquake cycle in the northern Chilean fore arc, Tectonics, 29(2), doi:10.1029/2009TC002465.

Lyakhovsky, V., Hamiel, Y. \& Ben-Zion, Y., 2011. A non-local visco-elastic damage model and dynamic fracturing, J. Mech. Phys. Solids, 59(9), 1752-1776.

Marone, C., 1998. Laboratory-derived friction laws and their application to seismic faulting, Ann. Rev. Earth planet. Sci., 26(1), 643-696.

Marone, C.J., Scholtz, C. \& Bilham, R., 1991. On the mechanics of earthquake afterslip, J. geophys. Res., 96(B5), 8441-8452.

McCaffrey, R., 2008. Global frequency of magnitude 9 earthquakes, Geology, 36(3), 263-266.

Mitchell, T. \& Faulkner, D., 2009. The nature and origin of off-fault damage surrounding strike-slip fault zones with a wide range of displacements: a field study from the Atacama Fault System, Northern Chile, J. Struct. Geol., 31(8), 802-816.

Miyake, Y. \& Noda, H., 2019. Fully dynamic earthquake sequence simulation of a fault in a viscoelastic medium using a spectral boundary integral equation method: does interseismic stress relaxation promote aseismic transients?, Earth, Planets Space, 71(1), 1-12.

Montési, L.G., 2004. Controls of shear zone rheology and tectonic loading on postseismic creep, J. geophys. Res., 109(B10), doi:10.1029/2003JB002925.

Moresi, L., Dufour, F. \& Mühlhaus, H.-B., 2003. A lagrangian integration point finite element method for large deformation modeling of viscoelastic geomaterials, J. Comput. Phys., 184(2), 476-497.

Nakatani, M., 2001. Conceptual and physical clarification of rate and state friction: frictional sliding as a thermally activated rheology, J. geophys. Res., 106(B7), 13 347-13 380.

Noda, H. \& Lapusta, N., 2013. Stable creeping fault segments can become destructive as a result of dynamic weakening, Nature, 493(7433), 518.

Obara, K. \& Kato, A., 2016. Connecting slow earthquakes to huge earthquakes, Science, 353(6296), 253-257.

Oleskevich, D., Hyndman, R. \& Wang, K., 1999. The updip and downdip limits to great subduction earthquakes: thermal and structural models of Cascadia, South Alaska, SW Japan, and Chile, J. geophys. Res., 104(B7), 14 965-14 991.

Palmer, A.C. \& Rice, J.R., 1973. The growth of slip surfaces in the progressive failure of over-consolidated clay, Proc. R. Soc. Lond., A, 332(1591), 527-548.

Peltzer, G., Rosen, P., Rogez, F. \& Hudnut, K., 1998. Poroelastic rebound along the Landers 1992 earthquake surface rupture, J. geophys. Res., 103(B12), 30 131-30 145.
Peng, Z. \& Gomberg, J., 2010. An integrated perspective of the continuum between earthquakes and slow-slip phenomena, Nat. Geosci., 3(9), 599.

Perfettini, H. \& Avouac, J.-P., 2004. Postseismic relaxation driven by brittle creep: a possible mechanism to reconcile geodetic measurements and the decay rate of aftershocks, application to the chi-chi earthquake, Taiwan, J. geophys. Res., 109(B2), doi:10.1029/2003JB002488.

Perfettini, H. et al., 2010. Seismic and aseismic slip on the central Peru megathrust, Nature, 465(7294), 78.

Pfiffner, O.A., 2017. Thick-skinned and thin-skinned tectonics: a global perspective, Geosciences, 7(3), doi:10.3390/geosciences7030071.

Philibosian, B. et al., 2017. Earthquake supercycles on the mentawai segment of the sunda megathrust in the seventeenth century and earlier, $J$. geophys. Res., 122(1), 642-676.

Platt, J.D., Rudnicki, J.W. \& Rice, J.R., 2014. Stability and localization of rapid shear in fluid-saturated fault gouge: 2. Localized zone width and strength evolution, J. geophys. Res., 119(5), 4334-4359.

Pozzi, G., De Paola, N., Nielsen, S.B., Holdsworth, R.E., Tesei, T., Thieme, M. \& Demouchy, S., 2021. Coseismic fault lubrication by viscous deformation, Nat. Geosci., 14, 437-442.

Pranger, C., Sanan, P., May, D., Le Pourhiet, L. \& Gabriel, A.-A., 2021. Rate and state friction as a spatially regularized transient viscous flow law, Earth Space Sci Open Arch.,

Preuss, S., Herrendörfer, R., Gerya, T., Ampuero, J.-P. \& van Dinther, Y., 2019. Seismic and aseismic fault growth lead to different fault orientations, J. geophys. Res., 124(8), 8867-8889.

Ranalli, G., 1995. Rheology of the Earth, Springer.

Ricard, Y. \& Bercovici, D., 2009. A continuum theory of grain size evolution and damage, J. geophys. Res., 114(B1), doi:10.1029/2007JB005491.

Rice, J.R., 1993. Spatio-temporal complexity of slip on a fault, J. geophys. Res., 98(B6), 9885-9907.

Rice, J.R., 2006. Heating and weakening of faults during earthquake slip, $J$. geophys. Res., 111(B5), doi:10.1029/2005JB004006.

Rice, J.R. \& Ruina, A.L., 1983. Stability of steady frictional slipping, $J$. Appl. Mech., 50(2), 343-349.

Rice, J.R., Lapusta, N. \& Ranjith, K., 2001. Rate and state dependent friction and the stability of sliding between elastically deformable solids, J. Mech. Phys. Solids, 49(9), 1865-1898.

Rice, J.R., Rudnicki, J.W. \& Platt, J.D., 2014. Stability and localization of rapid shear in fluid-saturated fault gouge: 1 . Linearized stability analysis, J. geophys. Res., 119(5), 4311-4333.

Rosenau, M. \& Oncken, O., 2009. Fore-arc deformation controls frequencysize distribution of megathrust earthquakes in subduction zones, J. geophys. Res., 114(B10), doi:10.1029/2009JB006359.

Rowe, C.D., Moore, J.C., Remitti, F. \& Scientists, I. E.T., 2013. The thickness of subduction plate boundary faults from the seafloor into the seismogenic zone, Geology, 41(9), 991-994.

Rubin, A.M. \& Ampuero, J.-P., 2005. Earthquake nucleation on (aging) rate and state faults, J. geophys. Res., 110(B11), doi:10.1029/2005JB003686.

Ruh, J.B., Kaus, B.J. \& Burg, J.-P., 2012. Numerical investigation of deformation mechanics in fold-and-thrust belts: Influence of rheology of single and multiple décollements, Tectonics, 31(3), doi:10.1029/2011TC003047.

Ruina, A., 1983. Slip instability and state variable friction laws, J. geophys. Res., 88(B12), 10 359-10 370.

Sallarès, V. \& Ranero, C.R., 2019. Upper-plate rigidity determines depthvarying rupture behaviour of megathrust earthquakes, Nature, 576(7785), 96-101.

Savage, J., 1983. A dislocation model of strain accumulation and release at a subduction zone, J. geophys. Res., 88(B6), 4984-4996.

Savage, J.C., Lisowski, M. \& Svarc, J.L., 1994. Postseismic deformation following the $1989(\mathrm{~m}=7.1)$ Loma Prieta, California, earthquake, J. geophys. Res., 99(B7), 13 757-13 765.

Schenk, O. \& Gärtner, K., 2004. Solving unsymmetric sparse systems of linear equations with Pardiso, Future Generat. Comp. Syst., 20(3), 475487. 
Schmalholz, S., Podladchikov, Y. \& Schmid, D., 2001. A spectral/finite difference method for simulating large deformations of heterogeneous, viscoelastic materials, J. geophys. Int., 145(1), 199-208.

Scholz, C.H., 1998. Earthquakes and friction laws, Nature, 391(6662), $37-$ 42.

Segall, P., Rubin, A.M., Bradley, A.M. \& Rice, J.R., 2010. Dilatant strengthening as a mechanism for slow slip events, J. geophys. Res., 115(B12), doi:10.1029/2010JB007449.

Sibson, R.H., 1982. Fault zone models, heat flow, and the depth distribution of earthquakes in the continental crust of the united states, Bull. seism. Soc. Am., 72(1), 151-163.

Sieh, K. et al., 2008. Earthquake supercycles inferred from sea-level changes recorded in the corals of west Sumatra, Science, 322(5908), 1674-1678.

Simons, M. et al., 2011. The 2011 magnitude 9.0 Tohoku-Oki earthquake: mosaicking the megathrust from seconds to centuries, science, 332(6036), $1421-1425$.

Sobolev, S.V. \& Muldashev, I.A., 2017. Modeling seismic cycles of great megathrust earthquakes across the scales with focus at postseismic phase, Geochem. Geophys. Geosyst., 18(12), 4387-4408.

Thakur, P. \& Huang, Y., 2021. Influence of fault zone maturity on fully dynamic earthquake cycles, 48(17), doi:10.1029/2021GL094679.

Thielmann, M., Rozel, A., Kaus, B. \& Ricard, Y., 2015. Intermediate-depth earthquake generation and shear zone formation caused by grain size reduction and shear heating, Geology, 43(9), 791-794.

Thomas, M.Y. \& Bhat, H.S., 2018. Dynamic evolution of off-fault medium during an earthquake: a micromechanics based model, J. geophys. Int., 214(2), 1267-1280.

Thomas, M.Y., Lapusta, N., Noda, H. \& Avouac, J.-P., 2014. Quasi-dynamic versus fully dynamic simulations of earthquakes and aseismic slip with and without enhanced coseismic weakening, J. geophys. Res., 119(3), 1986-2004

Tobin, H.J. \& Saffer, D.M., 2009. Elevated fluid pressure and extreme mechanical weakness of a plate boundary thrust, Nankai trough subduction zone, Geology, 37(8), 679-682.

Tse, S.T. \& Rice, J.R., 1986. Crustal earthquake instability in relation to the depth variation of frictional slip properties, J. geophys. Res., 91(B9), 9452-9472.
Tullis, T.E., 1996. Rock friction and its implications for earthquake prediction examined via models of Parkfield earthquakes, Proc. Natl. Acad. Sci., 93(9), 3803-3810.

Turcotte, D. \& Schubert, G., 2002. Geodynamics, Cambridge Univ. Press. van Dinther, Y., Gerya, T., Dalguer, L., Corbi, F., Funiciello, F. \& Mai, P.M., 2013a. The seismic cycle at subduction thrusts: 2 . Dynamic implications of geodynamic simulations validated with laboratory models, J. geophys. Res., 118(4), 1502-1525.

van Dinther, Y., Gerya, T., Dalguer, L., Mai, P.M., Morra, G. \& Giardini, D., 2013b. The seismic cycle at subduction thrusts: insights from seismothermo-mechanical models, J. geophys. Res., 118(12), 6183-6202.

van Dinther, Y., Mai, P.M., Dalguer, L. \& Gerya, T., 2014. Modeling the seismic cycle in subduction zones: the role and spatiotemporal occurrence of off-megathrust earthquakes, Geophys. Res. Lett., 41(4), 1194-1201.

van Rijsingen, E., Lallemand, S., Peyret, M., Arcay, D., Heuret, A., Funiciello, F. \& Corbi, F., 2018. How subduction interface roughness influences the occurrence of large interplate earthquakes, Geochem. Geophys. Geosyst., 19(8), 2342-2370.

Veedu, D.M. \& Barbot, S., 2016. The Parkfield tremors reveal slow and fast ruptures on the same asperity, Nature, 532(7599), 361-365.

Viesca, R.C. \& Dublanchet, P., 2018. The slow slip of viscous faults, $J$. geophys. Res., 124(5), 4959-4983.

Wang, K. \& Bilek, S.L., 2011. Do subducting seamounts generate or stop large earthquakes?, Geology, 39(9), 819-822.

Wang, K. \& Hu, Y., 2006. Accretionary prisms in subduction earthquake cycles: the theory of dynamic coulomb wedge, J. geophys. Res., 111(B6), doi: 10.1029/2005JB004094.

Wang, K., Hu, Y. \& He, J., 2012. Deformation cycles of subduction earthquakes in a viscoelastic earth, Nature, 484, 327-332.

Warren-Smith, E. et al., 2019. Episodic stress and fluid pressure cycling in subducting oceanic crust during slow slip, Nat. Geosci., 12(6), 475-481.

Ye, L., Kanamori, H. \& Lay, T., 2018. Global variations of large megathrust earthquake rupture characteristics, Sci. Adv., 4(3), doi:10.1126/sciadv.aao4915.

Zhu, W., Allison, K.L., Dunham, E.M. \& Yang, Y., 2020. Fault valving and pore pressure evolution in simulations of earthquake sequences and aseismic slip, Nat. Commun., 11(1), 1-11.

\section{APPENDIX A: DERIVATION OF A UNIFIED NON-LINEAR VISCOSITY}

When both diffusion $\left[\eta_{\text {diff }}\right.$ eq. (11)] and dislocation $\left[\eta_{\text {disl }}\right.$ - eq. (12)] creep mechanisms are simultaneously active $\left(N_{v}=2\right)$, an harmonic average is commonly used to obtain a single effective viscosity ( $\left.\eta_{\text {eff }}\right)$ (Gerya 2019):

$\eta_{\mathrm{eff}}=\left(\sum_{k=1}^{N_{v}} \frac{1}{\eta_{k}}\right)^{-1}=\frac{1}{\eta_{\mathrm{diff}}}+\frac{1}{\eta_{\mathrm{disl}}}$,

which can be rearranged such that:

$\eta_{\text {eff }}=\frac{\eta_{\text {diff }} \eta_{\text {disl }}}{\eta_{\text {diff }}+\eta_{\text {disl }}}$.

The second strain rate invariant for the dislocation creep $\left(\dot{\varepsilon}_{\mathrm{II}(\mathrm{disl})}\right)$ can be defined as:

$\dot{\varepsilon}_{\mathrm{II}(\mathrm{disl})}=\frac{\tau_{\mathrm{II}}}{2 \eta_{\mathrm{disl}}}$,

and by replacing the dislocation viscosity $\eta_{\text {disl }}$ with eq. (12) leads to

$\dot{\varepsilon}_{\mathrm{II}(\mathrm{dis})}=\frac{\tau_{\mathrm{II}}}{2 \frac{A_{d}^{\prime \frac{1}{n}}}{2} \varepsilon_{\mathrm{II}(\mathrm{disl})}^{\frac{1}{n}-1} \exp \left(\frac{E+p V}{n R T}\right)}$.

If we multiply the expression with $\dot{\varepsilon}_{\mathrm{II}(\mathrm{disl})}^{\frac{1}{n}-1}$, raise to the power of $n$, move the exponential function to the numerator, and replace $A_{d}=1 / A_{d}^{\prime}$, the second invariant of the strain rate becomes:

$\dot{\varepsilon}_{\mathrm{II}(\mathrm{disl})}=\tau_{\mathrm{II}}^{n} \exp \left(-\frac{E+p V}{R T}\right) A_{d}$. 
To obtain an expression for the dislocation viscosity, eq. (A3) can be rearranged:

$\eta_{\text {disl }}=\frac{1}{2 \tau_{\mathrm{II}}^{n-1} \exp \left(-\frac{E+p V}{R T}\right) A_{d}}$.

By inserting $Z$ from eq. (20), the deviatoric stress can be written as

$\tau_{i j}^{\prime}=\frac{\eta_{\text {eff }}}{\Delta t \mu+\eta_{\text {eff }}}\left(2 \dot{\varepsilon}_{i j} \mu \Delta t+\tau_{i j}^{\prime 0}\right)$,

which can be used to reformulate the expression of the second stress invariant $\tau_{\mathrm{II}}=\sqrt{\tau_{\mathrm{II}}^{\prime 2}+\tau_{i j}^{\prime 2}}$ as follows:

$$
\begin{aligned}
\tau_{\mathrm{II}} & =\sqrt{\left(\frac{\eta_{\mathrm{eff}}}{\Delta t \mu+\eta_{\mathrm{eff}}}\left(2 \dot{\varepsilon}_{\mathrm{II}} \mu \Delta t+\tau_{\mathrm{II}}^{\prime 0}\right)\right)^{2}+\left(\frac{\eta_{\mathrm{eff}}}{\Delta t \mu+\eta_{\mathrm{eff}}}\left(2 \dot{\varepsilon}_{i j} \mu \Delta t+\tau_{i j}^{\prime 0}\right)\right)^{2}} \\
& =\frac{\eta_{\mathrm{eff}}}{\Delta t \mu+\eta_{\mathrm{eff}}} \underbrace{\sqrt{\left(2 \dot{\varepsilon}_{\mathrm{II}} \mu \Delta t+\tau_{\mathrm{II}}^{\prime 0}\right)^{2}+\left(2 \dot{\varepsilon}_{i j} \mu \Delta t+\tau_{i j}^{\prime 0}\right)^{2}}}_{\tau_{\mathrm{II}}^{e}},
\end{aligned}
$$

where $\tau_{\text {II }}^{e}$ is the elastic component of the second stress invariant. Assuming eq. (A2), the effective viscosity can be replaced into the second stress invariant as:

$\tau_{\mathrm{II}}=\left(\frac{\eta_{\text {diff }} \eta_{\text {disl }}}{\Delta t \mu+\left(\eta_{\text {diff }}+\eta_{\text {disl }}\right)+\eta_{\text {diff }} \eta_{\text {disl }}}\right) \tau_{\text {II }}^{e}$

Introducing eq. (A9) into eq. (A6) we can reformulate the dislocation viscosity, which gives the final expression:

$$
\begin{aligned}
\eta_{\text {disl }} & =\frac{1}{\left(\frac{\eta_{\text {diff }} \eta_{\text {disl }} \tau_{\text {II }}^{e}}{\Delta t \mu+\left(\eta_{\text {diff }}+\eta_{\text {disl }}\right)+\eta_{\text {diff }} \eta_{\text {disl }}}\right)^{n-1} \exp \left(-\frac{E+p V}{R T}\right) A_{d}} \\
& =\left(\frac{\left(\frac{\eta_{\text {diff }}+\eta_{\text {disl }}}{\eta_{\text {diff }}}\left(\Delta t \mu+\eta_{\text {eff }}\right)\right)^{n-1}}{2 A_{d} \exp \left(-\frac{E+p V}{R T}\right)\left(\tau_{\mathrm{II}}^{e}\right)^{n-1}}\right)^{\frac{1}{n}} .
\end{aligned}
$$

\section{APPENDIX B: NEWTON-RAPHSON SCHEME TO SOLVE NON-LINEAR VISCOSITY}

In order to apply a consistent Newton-Raphson algorithm, eq. (A10) needs to be transformed into a root finding problem as follow (Blum 2019)

$f\left(\eta_{\text {disl }}\right)=\eta_{\text {disl }}-\left(\frac{\left(\frac{\eta_{\text {diff }}+\eta_{\text {disl }}}{\eta_{\text {diff }}}\left(\Delta t \mu+\eta_{\text {eff }}\right)\right)^{n-1}}{2 A_{d} \exp (-k)\left(\tau_{\mathrm{II}}^{e}\right)^{n-1}}\right)^{\frac{1}{n}}$,

where $k=(E+p V) /(R T)$ is the Arrhenius term. Before taking the derivative of the given function (B1), we introduce a new variable $Q$ to simplify the expression:

$Q=\frac{1}{2 A_{d} \exp (-k)\left(\tau_{\mathrm{II}}^{e}\right)^{n-1}}$.

The derivative of the function $f$ with respect to the dislocation viscosity is given by

$$
\begin{aligned}
& f^{\prime}\left(\eta_{\text {disl }}\right)=1-\frac{1}{n}\left(\left(\frac{\eta_{\text {diff }}+\eta_{\text {disl }}}{\eta_{\text {diff }}}\left(\Delta t \mu+\eta_{\text {eff }}\right)\right)^{n-1} Q\right)^{\frac{1-n}{n}}(n-1) \ldots \\
& \left(\frac{\eta_{\text {diff }}+\eta_{\text {disl }}}{\eta_{\text {diff }}}\left(\Delta t \mu+\eta_{\text {eff }}\right)\right)^{n-2} Q\left(\frac{1}{\eta_{\text {diff }}}\left(\Delta t \mu+\eta_{\text {eff }}\right)+\frac{\eta_{\text {diff }}+\eta_{\text {disl }}}{\eta_{\text {diff }}}\left(\Delta t \mu+\eta_{\text {eff }}\right)^{\prime}\right) .
\end{aligned}
$$

Since $(\Delta t \mu)$ is independent of $\eta_{\text {disl }}$, it can be removed in the last derivative. Using the product rule and rearranging the terms lead to

$f^{\prime}\left(\eta_{\text {disl }}\right)=1-\frac{n-1}{\eta_{\text {diff }} n} Q^{\frac{1}{n}}\left(\frac{\eta_{\text {diff }}+\eta_{\text {disl }}}{\eta_{\text {diff }}}\left(\Delta t \mu+\eta_{\text {eff }}\right)\right)^{-\frac{1}{n}}\left(\left(\Delta t \mu+\eta_{\text {eff }}\right)+\frac{\eta_{\text {diff }}^{2}+\eta_{\text {disl }}}{\eta_{\text {diff }}}\right)$.

Finally all required terms (eq. B1) were computed to calculate the next iterate:

$\eta_{\text {disl }}^{(t+1)}=\eta_{\text {disl }}^{(t)}-\frac{f\left(\eta_{\text {disl }}^{(t)}\right)}{f^{\prime}\left(\eta_{\text {disl }}^{(t)}\right)}$ 
In order to start the Newton-Raphson algorithm, an initial guess $x^{(0)}$ is required for a root of the function $f$. An initial guess that is reasonably close to the true root is

$x^{(0)}=\frac{1}{A_{d} \exp \left(-\frac{E+p V}{R T}\right)\left(\tau_{\mathrm{II}}^{e}\right)^{n-1}}$.

Lastly, we define the stopping criteria as the absolute logarithmic difference between two iteration steps

$\left|\log _{10}\left(\frac{\eta_{\mathrm{eff}}^{(t)}}{\eta_{\mathrm{eff}}^{(t-1)}}\right)\right|<\delta$,

where $\delta=-6$ defines the tolerance. 